\title{
Effects of Chronic Stress on Prefrontal Cortex Transcriptome in Mice Displaying Different Genetic Backgrounds
}

\author{
Pawel Lisowski • Marek Wieczorek • Joanna Goscik • \\ Grzegorz R. Juszczak • Adrian M. Stankiewicz • \\ Lech Zwierzchowski • Artur H. Swiergiel
}

Received: 14 May 2012 / Accepted: 25 June 2012 / Published online: 27 July 2012

(C) The Author(s) 2012. This article is published with open access at Springerlink.com

\begin{abstract}
There is increasing evidence that depression derives from the impact of environmental pressure on genetically susceptible individuals. We analyzed the effects of chronic mild stress (CMS) on prefrontal cortex transcriptome of two strains of mice bred for high (HA)and low (LA) swim stress-induced analgesia that differ in basal transcriptomic profiles and depressionlike behaviors. We found that CMS affected 96 and 92 genes in HA and LA mice, respectively. Among genes with the same expression pattern in both strains after CMS, we observed robust upregulation of Ttr gene coding transthyretin involved in amyloidosis, seizures, stroke-like episodes, or dementia. Strain-specific HA transcriptome affected by CMS was associated with deregulation of genes involved in insulin secretion (Acvrlc, Nnat, and Pfkm), neuropeptide hormone activity (Nts and Trh), and dopamine receptor mediated
\end{abstract}

Electronic supplementary material The online version of this article (doi:10.1007/s12031-012-9850-1) contains supplementary material, which is available to authorized users.

P. Lisowski $(\bowtie) \cdot$ L. Zwierzchowski

Department of Molecular Biology, Institute of Genetics and Animal Breeding, Polish Academy of Sciences,

Postepu 1, 05-552 Jastrzebiec n/Warsaw,

Warsaw, Poland

e-mail: p.lisowski@ighz.pl

\section{Wieczorek}

Department of Neurobiology, Faculty of Biology and Environmental Protection, University of Lodz, Pomorska 141/143,

90-236 Lodz, Poland

J. Goscik

Centre for Experimental Medicine,

Medical University of Bialystok,

Marii Sklodowskiej-Curie 24A,

15-276 Bialystok, Poland signaling pathway (Clic6, Drdla, and Ppp1r1b). LA transcriptome affected by CMS was associated with genes involved in behavioral response to stimulus (Fcerlg, Rasd2, S100a8, S100a9, Crhr1, Grm5, and Prkcc), immune effector processes (Fcerlg, Mpo, and Igh-VJ558), diacylglycerol binding (Rasgrpl, Dgke, $D g k g$, and Prkcc), and long-term depression (Crhrl, Grm5, and Prkcc) and/or coding elements of dendrites (Crmp 1, Cntnap4, and Prkcc) and myelin proteins (Gpm6a, Mal, and Mog). The results indicate significant contribution of genetic background to differences in stress response gene expression in the mouse prefrontal cortex.

Keywords Analgesia · Chronic mild stress · Gene expression · Microarray $\cdot$ Mouse $\cdot$ Pain $\cdot$ Prefrontal cortex Transcriptome $\cdot$ Transthyretin

J. Goscik

Department of Software Engineering,

Bialystok Technical University,

Wiejska 45A,

15-351 Bialystok, Poland

G. R. Juszczak · A. M. Stankiewicz · A. H. Swiergiel

Department of Animal Behavior, Institute of Genetics and Animal

Breeding, Polish Academy of Sciences,

Postepu 1, 05-552 Jastrzebiec n/Warsaw,

Warsaw, Poland

A. H. Swiergiel

Department of Animal Physiology, Institute of Biology,

Gdansk University,

Kladki 4,

80-882 Gdansk, Poland 


\section{Introduction}

Exposure to stress is thought to precipitate several neuropsychiatric disorders (Mazure et al. 1995). Chronic stress has significant impact on the cellular integrity and function of certain brain areas, most notably the limbic structures (Joels et al. 2007; McEwen 2006). In most studies, the hippocampal formation has been investigated as a crucial structure, but recently the prefrontal cortex (PFC) has been seen as equally important (Czeh et al. 2008).

Prefrontal cortex in rodents participates in the higherorder functions including learning, memory, event association, the temporal sequencing of tasks, specific aspects of locomotor activity, spatial navigation, decision making, and goal-directed behavior (Pirot et al. 1994; Vertes 2006). PFC plays a key role in working memory, recalling memories from long-term storage, as well as recent memories to guide behavior, while inhibiting inappropriate responses and distractions (Ramos and Arnsten 2007; Robbins 1996). All of these abilities depend on proper PFC network connections, which are vulnerable to stress and neurochemical environment (Arnsten 2009). PFC contributes to negative feedback control of the hypothalamic-pituitary-adrenal axis (HPA) (Herman et al. 2003) and regulates the stress responses of other structures (Amat et al. 2005; Pascucci et al. 2007). Based on observations from clinical, neuropsychological, and neuroimaging studies, dysfunction of the PFC has been suspected to be accountable for some depressive symptoms (Cummings 1992; Deutch 1993; Fibiger 1995). Dolan et al. (1994) have provided evidence that neuropsychological symptoms in depression are associated with profound hypometabolism, particularly involving the medial PFC (Dolan et al. 1994). Both bipolar and unipolar affective disorders can be identified by decreases in cerebral blood flow and the rate of glucose metabolism in the PFC (Drevets 2000; Drevets et al. 1997).

Animal studies indicate that exposure to acute or chronic stress can alter the activity of the neuroendocrine and neurotransmitter systems that affect behavior. Stress in rodents induces anxiety, enhanced fear, anhedonia, and depression (Bekris et al. 2005; Bergstrom et al. 2008; D'Aquila et al. 1994; Wood et al. 2008). Chronic stress reduces dopaminergic and serotonergic transmission in the PFC (Mizoguchi et al. 2002) and results in a depressive state. Exposure to mild uncontrollable stress impairs PFC functions in humans and animals (Arnsten 2009). Loss of self-control during stress can lead to maladaptive behaviors such as alcohol and drug addiction, smoking, and overeating ( $\mathrm{Li}$ and Sinha 2008). Stress can also exacerbate the symptoms of bipolar disorders and schizophrenia (Breier et al. 1991; Dohrenwend 1994).

Preclinical observations can help to understand stressrelated processes in the human brain of genetically stressvulnerable individuals. Because the responses should differ between the subjects displaying different sensitivity to stress, in the present study we investigated the effects of chronic mild stress (CMS) on gene expression in the frontal cortex of mice selected for high (HA strain) or low (LA strain) stress reaction measured by magnitude of swim stress-induced analgesia (Panocka et al. 1986b). The unstressed strains display profound differences in a number of behavioral tests reflecting anxiety or depression. HA mice exhibit higher acoustic startle response (Błaszczyk et al. 2000; Juszczak et al. 2008a) and longer depression-like behavior (immobility) in the tail suspension (TST) and forced swim (FST) tests (Juszczak et al. 2008b, 2006; Panocka et al. 2001) than the LA strain. The strains also differ in responses to a variety of antidepressants. Desipramine (a prototypic tricylic antidepressant), venlafaxine (selective serotonin reuptake inhibitor), and aminosenktide (tachykinin NK3 - receptor agonist) shortened the immobility time of HA mice in the FST or TST, but were ineffective in the LA strain (Juszczak et al. 2006; Panocka et al. 2001).

Using gene expression profiling and bioinformatics methodology we now attempted to identify candidate genes, physiological pathways, and potential mechanisms of mood disorders in the PFC of mice that differ in depression-like responses and are exposed to CMS.

\section{Experimental Procedures}

\section{Animals}

Male Swiss Webster mice (weighing 25-30 g, 12 weeks of age), from two lines selected for 76 generations for high (HA) and low (LA) swim stress-induced analgesia (SIA) were used (Panocka et al. 1986a). Adult males and females from each generation, after completion of 3-min swim in $20{ }^{\circ} \mathrm{C}$ water, were tested for pain sensitivity on a hot-plate heated to $56^{\circ} \mathrm{C}$. Latency of characteristic hind paw flick or lick response was scored. The animals displaying the longest (50-60 s) and the shortest ( $<10 \mathrm{~s})$ post-swim latencies of the nociceptive response were chosen for further breeding. Animals were given ordinary daily care with free access to food and water and kept at ambient temperature of $22 \pm 1^{\circ} \mathrm{C}$. All procedures had been approved by the Local Ethics Commission and carried out in accordance with the Guiding Principles for the Care and Use of Research Animals.

\section{Chronic Mild Stress}

The animals were assigned to two treatment groups. Control animals (control HA mice, $n=15$, and control LA mice, $n=$ 15 ) were given ordinary daily care with free access to food and water, while the stressed animals were exposed for 5 weeks to chronic mild stress (CMS HA mice, $n=15$, and 
CMS LA mice, $n=15$ ). CMS was adapted from the procedures developed by Willner et al. (1987) and used in our previous study, Lisowski et al. (2011). Stressors were applied in a pseudo-random manner during both light and dark phases. All mice received the same treatment schedule, with treatments occurring in different orders in different weeks. The control and CMS groups of mice were housed in single cages and separately in different rooms.

\section{Sample Preparation}

Two days after the end of the CMS, the animals were gently removed from their cages and quickly decapitated within $30 \mathrm{~s}$, the brains were removed and placed on ice-cold glass dish, and prefrontal cortices were immediately isolated (Hamon 2006), aliquoted into freezing vials, frozen in liquid nitrogen, and stored at $-80^{\circ} \mathrm{C}$ until analysis. Total RNA was isolated, separately from each prefrontal cortex, using NucleoSpin RNA II kit (Macherey-Nagel, Germany), according to the manufacturer's protocol. Nanodrop (Nanodrop, USA) and Bioanalyzer (Agilent, USA) estimated quantity and quality of each RNA sample, and the RIN (RNA Integrity Number) index ranged from 9.4 to 9.8 for all samples.

For each microarray, total RNA samples from five animals were pooled and quantity and quality of the pooled samples estimated once again by the Nanodrop and Bioanalyzer. Biotinylated cRNA was prepared using the Illumina RNA Amplification Kit (Ambion Inc., USA) according to the manufacturer's protocol and starting with $100 \mathrm{ng}$ total RNA. Samples were purified with the RNeasy kit (Qiagen, Germany) according to the manufacturer's protocol.

\section{Microarray, Hybridization, and Fluorescent Detection}

Hybridization to the Sentrix MouseRef-8 Expression BeadChip (Illumina, USA), washing, and scanning were performed according to the Illumina BeadStation 500x manual. Sentrix MouseRef-8 Expression BeadChip contains approximately 24,000 well-annotated RefSeq 50-mer oligonucleotide probes per array. Data were extracted using software provided by the manufacturer. Illumina Beadstudio v2 software with the default settings for gene expression analysis was used.

Data Normalization and Selection of Differentially Expressed Genes

Raw microarray data were processed with BeadArray and LIMMA package of the Bioconductor project (Bioconductor project; www.bioconductor.org). Data preprocessing step involved normalization of expression levels with quantile method was preceded by $\log 2$ transformation. Linear model fitting was performed for the pre-processed dataset. The empirical Bayes analysis was performed in order to identify differentially expressed genes by testing whether the contrast coefficients from the linear models can be assumed equal zero. Genes considered to be significantly differentially expressed with logged fold-change are greater than 0.5 and adjusted $p$ value is less than 0.05. Benjamini and Hochberg method (1995), for controlling false discovery rate, was used to correct $p$ values.

Bioinformatics, Database Search, and Gene Enrichment Analysis

\section{Gene Ontology Analysis}

Gene lists (GenBank accession numbers) from microarray results were submitted to the Expression Analysis Systemic Explorer (EASE; http://david.abcc.ncifcrf.gov). EASE takes into account the frequencies of genes belonging to particular Gene Ontology terms (GO; http://www.geneontology.org/ index.shtml) among the genes found to be regulated and among all genes studied in the experiment. EASE performs statistical analysis to detect overrepresented functional gene categories in the data set compared with all genes on the arrays. GO terms are reported with corresponding EASE scores-it is a conservative statistical test that gives the upper bound of the distribution of the Jackknife Fisher exact probabilities and favors robust categories. Functional gene categories were considered significantly overrepresented at $p<0.05$. Genes to functional categories were classified with biological process, molecular function, and cellular component ontologies.

\section{KEGG Biochemical Pathways Analysis}

Analysis of the genes' association with physiological pathways was performed using the Kyoto Encyclopedia of Genes and Genomes database (KEGG; http://www.genome.jp/kegg/ pathway.html). In KEGG database, distributions of the differentially expressed genes were classified among biochemical pathways. Microarray data from a single gene in a pathway do not suffice to describe a regulatory mechanism of the pathway. Therefore, only pathways with the microarray information for at least two genes were considered. To identify significantly overrepresented biological categories and KEGG pathways within the lists of differentially expressed genes, the threshold of EASE Score for the enrichment analysis was set at $p \leq 0.05$.

\section{Functional Clustering}

For a more insightful view of the relationships between annotation categories compared with chart, genes were clustered in the DAVID 6.7 Functional Annotation Clustering 
module (http://david.abcc.ncifcrf.gov/). Biologically meaningful clusters consist of genes that are annotated into specific functional annotation groups. Grouping genes based on functional similarity can systematically enhance biological interpretation of large lists of genes derived from high throughput studies. The Functional Classification Tool generates a gene-to-gene similarity matrix based on shared functional annotation using over 75,000 terms from 14 functional annotation sources. DAVID clustering algorithms classifies highly related genes into functionally related groups. The classification stringency of the cluster analysis was set at "high" level. To avoid over-counting duplicated genes in the chart report view, the Fisher exact statistics was calculated based on corresponding DAVID gene IDs by which all redundancies in original IDs are removed.

\section{Quantitative Real-Time Reverse Transcription PCR}

To validate the results of microarrays, quantitative real-time RT-PCR (qPCR) with SYBR Green technique was performed as described previously (Lisowski et al. 2011). Seven genes belonging to different functional groups and significantly differing in expression between the control and CMS mice of each strain were selected. qPCR assays were carried out in triplicates on the same but non-pooled individual RNA samples $(n=15)$ per experimental group RNA samples, which were used in the microarray experiment. For reference, two housekeeping genes, selected from ten commonly used reference genes using previous methodology (Lisowski et al. 2008a, b) stably expressed in mouse hippocampus in applied experimental assay and belonging to different functional classes, were used: glyceraldehyde-3-phosphate dehydrogenase (Gapdh) and hypoxanthine guanine phosphoribosyl transferase 1 (Hprt1). Primers were designed using ExonPrimer software (http://ihg2.helmholtz-muenchen.de/ihg/ExonPrimer.html) (Institute of Human Genetics, TUM/Helmholtz Center Munich, Germany) using Mus musculus GenBank sequences. All primers produced amplicons which spanned two exons each in highly conserved coding regions and included all known alternatively spliced mRNA variants

Data from three runs were calibrated by calculating the average cycle threshold value over samples in each run and the results were calculated using the mathematical model for relative quantification in qPCR described by Pfaffl (2001). To test for the effects of the observational groups on target genes mRNA level, t-test was performed (SAS version 8.02; SAS Institute, NC). Results are reported as the mean \pm standard error of the mean (SEM). Differences between the groups were considered significant at $p<0.05$. The degree of significance and the correlation between fold changes, as determined in the microarray analysis and those determined by qPCR, was evaluated with the Pearson moment correlation.

\section{Results}

Expression profiling was designed to determine the impact of genetic background (two selectively bred strains) on the transcriptional effects of CMS in prefrontal cortex. Gene analysis was performed by one color hybridization of the $24 \mathrm{~K}$ microarray in HA and LA, naïve and CMS mice. Three independent biological replicates of microarray were prepared for each group of mice. To minimize the influence of individual differences between the animals and variation introduced by dissection and tissue preparation, total RNA separately isolated from several PFCs was pooled. Each pool, containing total RNA from five individuals, was separately converted to cRNA and hybridized to a single microarray.

The identified genes are considered to be expressed in the prefrontal cortex according to Novartis Gene Expression Atlas (http://www.biogps.gnf.org/). Cell-type classification analysis of differentially expressed genes, according to Cahoy (2008), GeneCards Database (http://www.genecards.org/) screening and Ingenuity Pathway Analysis (IPA) (http:// www.ingenuity.com/) of top canonical pathways, revealed that most of them are characteristic for neurons and oligodendrocytes.

Differences in Basal Gene Expression of HA Mice Compared to LA

Comparison of basal gene expression profiles between the HA and LA strains identified 193 transcripts with different levels of mRNA in the PFC that met the criteria of logged fold change greater than 0.5 and $p<0.05$. One hundred thirty-three of differentially expressed genes between the strains were upregulated and 60 genes were downregulated in HA as compared to LA. Expression of these genes differs at baseline in a genotype-dependent manner. The whole sets of probes that differed in naive HA vs. LA mice are presented in "Electronic Supplementary Material" (ESM) Table S1. Genes annotated to these probe sets were considered to be expressed in the examined brain tissue according to Novartis Gene Expression Atlas (www.biogps.gnf.org).

Statistically significant $(p<0.05)$ over-expressed biological processes terms associated with the up- and downregulated genes between strains were found with the DAVID Functional Annotation Tool. We identified functional categories of biological process (Fig. 1), molecular function (Fig. 2), and KEGG biochemical pathways terms (Fig. 3), including elements of neuron development and differentiation, dendrite development, protein transport and localization, lipid binding, 


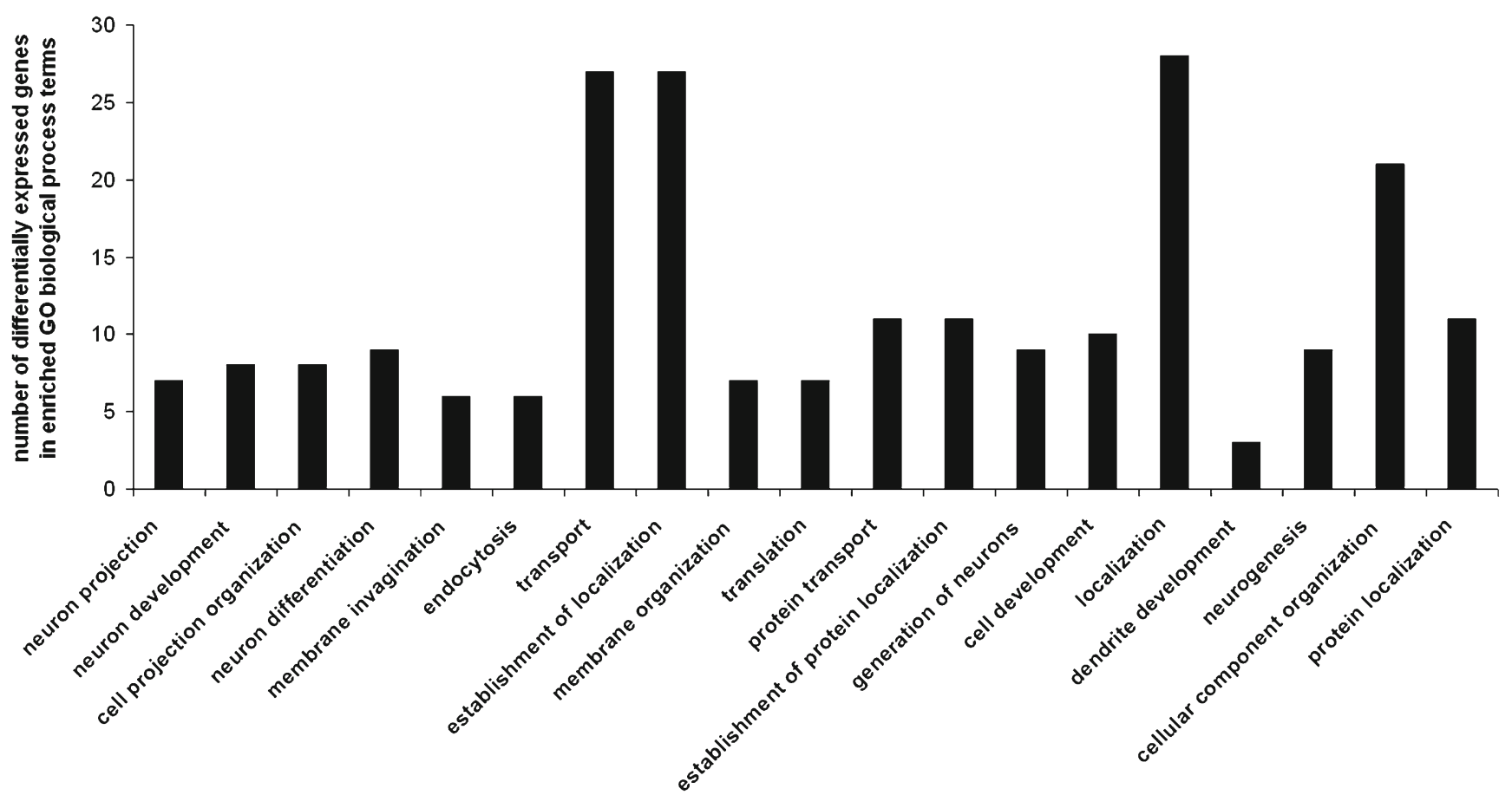

Fig. 1 Significantly enriched $(p<0.05)$ gene ontology $(\mathrm{GO})$ biological process categories of differentially expressed genes in the prefrontal cortex of naïve high analgesia (HA) vs. naïve low analgesia (LA) mice

calcium ion binding, phosphoinositide binding, cytoskeletal regulatory protein binding, long-term potentiation, VEGF, MAPK, and/or T cell signaling pathways.

GO and KEGG classifications on a list of significant upregulated transcripts was done in each strain. In general, genes upregulated in HA encode elements involved in processes such as dendrite development (Mtap2, Mtap1b, and Pak1), neuron projection (Mtap2, Mtap1b, Stxbp1, Etv1, and Pak1), cell communication (Kiflb, Snx14, Snx17, Clstn1, Stxbp1, Snx2, and Ppp3ca), synaptic transmission (Kiflb, Clstn1,
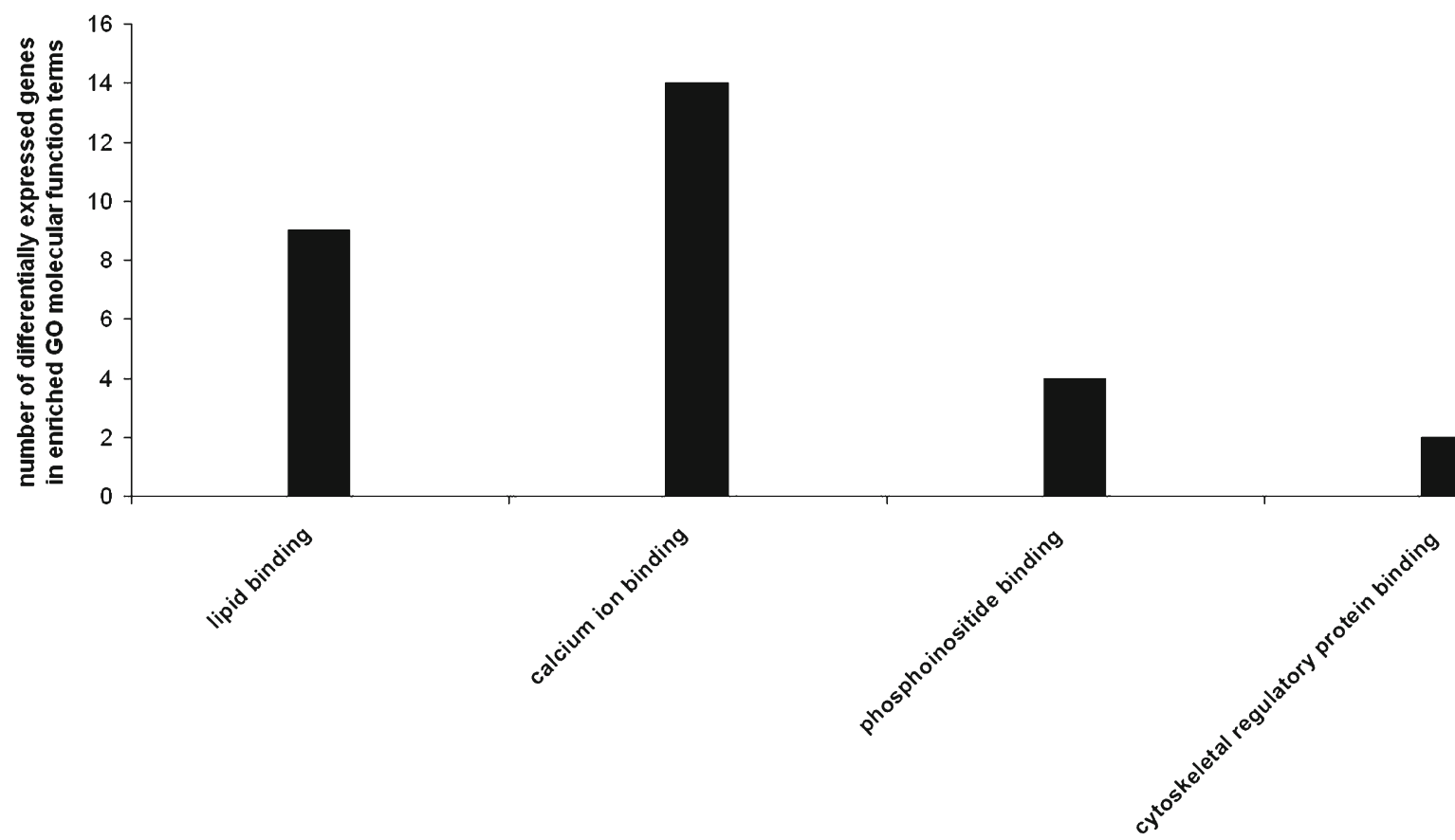

Fig. 2 Significantly enriched $(p<0.05)$ gene ontology $(\mathrm{GO})$ molecular function categories of differentially expressed genes in the prefrontal cortex of naïve high analgesia (HA) vs. naïve low analgesia (LA) mice 


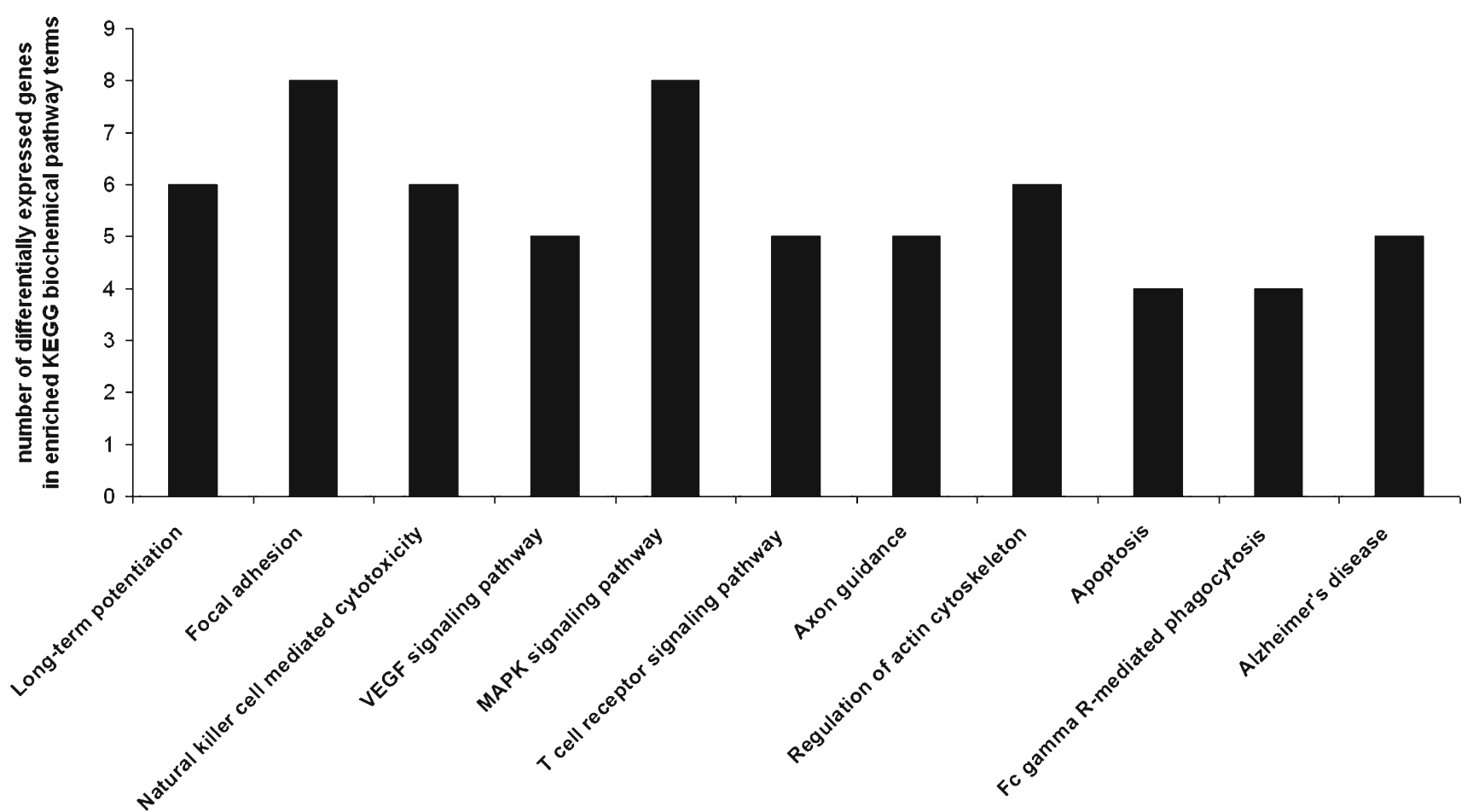

Fig. 3 Significantly enriched $(p<0.05)$ Kyoto Encyclopedia of Genes and Genomes (KEGG) biochemical pathways of differentially expressed genes in the prefrontal cortex of naïve high analgesia (HA) vs. naïve low analgesia (LA) mice

Stxbp1, and Ppp3ca), lipid binding (Snap91, Dgke, Snx14, Rasgrp1, Snx17, Snx2, Prkcc, and Sh3gl2), and calcium ion binding (Atp2c1, Rasgrp1, Itgav, Clstn1, Cacng3, Kcnip2, Capn2, Prkcc, 1500003003rik, and Dtna) (Tables 1 and 2).
To find significantly over-represented pathways in the list of differentially expressed genes, we searched the KEGG database. In the HA mice prefrontal cortex, significantly overrepresented pathways were the long-term potentiation,

Table 1 Upregulated genes associated with the gene ontology (GO) biological process terms $(p<0.05)$ in the prefrontal cortex of high analgesia (HA) mice

\begin{tabular}{|c|c|c|c|}
\hline GO biological process & Number of genes & EASE score & Genes \\
\hline Endocytosis & 6 & 0.002 & CAV2, ITGAV, SNX17, STXBP1, SH3GL2, ELMO1 \\
\hline Membrane organization & 7 & 0.002 & CAV2, SNAP91, ITGAV, SNX17, STXBP1, SH3GL2, ELMO1 \\
\hline Organelle organization & 12 & 0.014 & $\begin{array}{l}\text { TSPYL1, EPB4,1L3, CAV2, SNAP91, ATP2C1, MTAP2, MTAP1B, } \\
\text { STXBP1, CBX3, ACIN1, RBBP7, ELMO1 }\end{array}$ \\
\hline Transport & 20 & 0.016 & $\begin{array}{l}\text { GDI1, CAV2, SNAP91, SNX14, KCNAB1, SNX17, STXBP1, SNX2, } \\
\text { ATP6V1G2, CACNG3, KCNIP2, ELMO1, RAB7, SLCO1A4, } \\
\text { KIF1B, ATP2C1, ITGAV, PPP3CA, SH3GL2, SEC61A2 }\end{array}$ \\
\hline Dendrite development & 3 & 0.016 & MTAP2, MTAP1B, PAK1 \\
\hline Establishment of localization & 20 & 0.017 & $\begin{array}{l}\text { GDI1, CAV2, SNAP91, SNX14, KCNAB1, SNX17, STXBP1, SNX2, } \\
\text { ATP6V1G2, CACNG3, KCNIP2, ELMO1, RAB7, SLCO1A4, } \\
\text { KIF1B, ATP2C1, ITGAV, PPP3CA, SH3GL2, SEC61A2 }\end{array}$ \\
\hline Cellular component organization & 17 & 0.018 & $\begin{array}{l}\text { CAV2, SNAP91, MTAP2, SNX17, STXBP1, CBX3, RBBP7, ELMO1, } \\
\text { TSPYL1, EPB4,1L3, ATP2C1, ITGAV, MTAP1B, ETV1, PAK1, } \\
\text { ACIN1, SH3GL2 }\end{array}$ \\
\hline Neuron projection & 5 & 0.023 & MTAP2, MTAP1B, STXBP1, ETV1, PAK1 \\
\hline Vesicle-mediated transport & 7 & 0.027 & CAV2, SNAP91, ITGAV, SNX17, STXBP1, SH3GL2, ELMO1 \\
\hline Cell communication & 7 & 0.028 & KIF1B, SNX14, SNX17, CLSTN1, STXBP1, SNX2, PPP3CA \\
\hline Protein transport & 8 & 0.040 & GDI1, SNX14, SNX17, STXBP1, SNX2, PPP3CA, SEC61A2, RAB7 \\
\hline Synaptic transmission & 4 & 0.040 & KIF1B, CLSTN1, STXBP1, PPP3CA \\
\hline
\end{tabular}


Table 2 Upregulated genes associated with the gene ontology (GO) molecular function terms $(p<0.05)$ in the prefrontal cortex of high analgesia (HA) mice

\begin{tabular}{|c|c|c|c|}
\hline GO molecular function & Number of genes & EASE score & Genes \\
\hline Lipid binding & 8 & 0.002 & $\begin{array}{l}\text { SNAP91, DGKE, SNX14, RASGRP1, SNX17, SNX2, PRKCC, } \\
\text { SH3GL2 }\end{array}$ \\
\hline Phosphoinositide binding & 4 & 0.006 & SNAP91, SNX14, SNX17, SNX2 \\
\hline Cytoskeletal regulatory protein binding & 2 & 0.017 & MTAP2, MTAP1B \\
\hline Phospholipid binding & 4 & 0.024 & SNAP91, SNX14, SNX17, SNX2 \\
\hline Calcium ion binding & 10 & 0.025 & $\begin{array}{l}\text { ATP2C1, RASGRP1, ITGAV, CLSTN1, CACNG3, KCNIP2, } \\
\text { CAPN2, PRKCC, 1500003O03RIK, DTNA }\end{array}$ \\
\hline Protein binding & 39 & 0.026 & $\begin{array}{l}\text { CAV2, SNAP91, SNX14, SNX17, CLSTN1, SNX2, CBX3, } \\
\text { ATP6V1G2, COPS8, ARPC5, FBXW7, SFRS5, CASP9, } \\
\text { ITGAV, INSIG1, BTBD3, ZFP238, PPP3CA, PAK1, RNF14, } \\
\text { SEC61A2, DTNA, MTAP2, EEF1A2, STXBP1, CAPN2, } \\
\text { RBBP7, } \\
\text { PPP1CB, ELMO1, EPB4,1L3, MAPK1, ATF4, KIF1B, BTG1, } \\
\text { MTAP1B, LASS1, HSPD1, CD200, SH3GL2 }\end{array}$ \\
\hline Diacylglycerol binding & 3 & 0.035 & DGKE, RASGRP1, PRKCC \\
\hline
\end{tabular}

focal adhesion, NK mediated cytotoxicity, VEGF, MAPK, T cell receptor, axon guidance, regulation of actin cytoskeleton, apoptosis, Fc gamma R-mediated phagocytosis and Alzheimer's disease pathways (Table 3).

Genes upregulated in LA are involved in neuron differentiation (Sema5a, Exoc7, Pcsk9, and Rpgrip1), response to stimulus (Crhr1, Bat5, Ercc5, S100a8, Camp, S100a9, Pcsk9, Mpo, Rpgrip1, and Psmb9), structural constituent of ribosome (Mrps 18c, Rpl6, and Rps15a), and coding cellular components such as cytosol and cytoplasmic parts (Actb, Bat5, Exoc7, Camp, Rps15a, Psmb9, Mrps18c, Rpl6, Tor1b, Pcsk9, Ltf, Mpo, Neu1, Pdrg1, Tomm22, Slc4a1, Hbb-b2, and Srp9), cell cortex parts (Actb, Exoc7, and Slc4a1), macromolecular complex (Bat5, Mrps18c, Kif3a, Exoc7, Rpl6, Rps15a, Pdrg1, Hbb-b2, Srp9, Itgbl1, and Psmb9), secretory granule and cytoplasmic membranebounded vesicle (Camp, Mpo, Ltf, and Neul), and ribosome (Mrps 18c, Rpl6, and Rps15a) (Tables 4 and 5). Among the genes upregulated in LA mice, no statistically significant KEGG biochemical pathways were found.

Effects of Chronic Mild Stress on Gene Expression in HA and LA Mice

The influence of genetic background on gene expression level was estimated. Using the same statistical criteria, the

Table 3 Upregulated genes associated with the Kyoto Encyclopedia of Genes and Genomes (KEGG) biochemical pathways $(p<0.05)$ in the prefrontal cortex of high analgesia (HA) mice

\begin{tabular}{|c|c|c|c|}
\hline KEGG biochemical pathway & Number of genes & EASE score & Genes \\
\hline Long-term potentiation & 6 & 0.000 & $\begin{array}{l}\text { MAPK1, ATF4, PPP3CA, PPP1CB, PRKCC, } \\
\text { 1500003O03RIK }\end{array}$ \\
\hline Natural killer cell-mediated cytotoxicity & 6 & 0.001 & $\begin{array}{l}\text { MAPK1, H2-T23, PPP3CA, PAK1, PRKCC, } \\
\text { 1500003O03RIK }\end{array}$ \\
\hline MAPK signaling pathway & 8 & 0.001 & $\begin{array}{l}\text { MAPK1, ATF4, RASGRP1, CACNG3, PPP3CA, PAK1, } \\
\text { PRKCC, 1500003O03RIK }\end{array}$ \\
\hline Focal adhesion & 7 & 0.001 & MAPK1, CAV2, ITGAV, PAK1, CAPN2, PPP1CB, PRKCC \\
\hline VEGF signaling pathway & 5 & 0.001 & MAPK1, CASP9, PPP3CA, PRKCC, 1500003O03RIK \\
\hline $\mathrm{T}$ cell receptor signaling pathway & 5 & 0.004 & MAPK1, RASGRP1, PPP3CA, PAK1, 1500003O03RIK \\
\hline Apoptosis & 4 & 0.014 & CASP9, PPP3CA, CAPN2, 1500003O03RIK \\
\hline Alzheimer's disease & 5 & 0.015 & MAPK1, CASP9, PPP3CA, CAPN2, 1500003O03RIK \\
\hline Fc gamma R-mediated phagocytosis & 4 & 0.017 & MAPK1, PAK1, ARPC5, PRKCC \\
\hline Regulation of actin cytoskeleton & 5 & 0.036 & MAPK1, ITGAV, PAK1, ARPC5, PPP1CB \\
\hline Axon guidance & 4 & 0.038 & MAPK1, PPP3CA, PAK1, 1500003O03RIK \\
\hline Amyotrophic lateral sclerosis (ALS) & 3 & 0.042 & CASP9, PPP3CA, 1500003O03RIK \\
\hline
\end{tabular}


Table 4 Upregulated genes associated with the gene ontology (GO) biological process terms $(p<0.05)$ in the prefrontal cortex of low analgesia (LA) mice

\begin{tabular}{lccl}
\hline GO biological process & Number of genes & EASE score & Genes \\
\hline $\begin{array}{l}\text { Neuron differentiation } \\
\text { Response to stimulus }\end{array}$ & 4 & 0.046 & $\begin{array}{l}\text { SEMA5A, EXOC7, PCSK9, RPGRIP1 } \\
\text { CRHR1, BAT5, ERCC5, S100A8, CAMP, } \\
\text { S100A9, PCSK9, MPO, RPGRI, PSMB9 }\end{array}$ \\
\begin{tabular}{lcc} 
Generation of neurons \\
\hline
\end{tabular} & 4 & 0.048 & SEMA5A, EXOC7, PCSK9, RPGRIP1 \\
\hline
\end{tabular}

comparisons of PFC transcriptomic profiles of naive vs. CMS animals revealed 96 in HA and 92 in LA differentially expressed transcripts. In HA strain, 59 of differentially expressed were upregulated and 37 genes were downregulated after CMS (ESM Table S2), while in LA strain, 60 genes were upregulated and 32 were downregulated as a result of CMS (ESM Table S3). There was also some overlap in the expression profiles between the strains: 23 common transcripts were changed in both strains (Table 6). Within the list of the overlapping genes, according to DAVID Functional Clustering Tool, eight genes coded cell membrane parts (Rab5b, Cntnap4, Ai593442, Pigt, Tomm22, $\operatorname{Rgs} 9$, Rasd2, and Calb2), six genes were classified into signal transduction and intracellular signaling cascade cluster (Rab5b, Cntnap4, Dgkg, Rgs9, Mtss1l, and Rasd2), three genes into ion binding cluster (Dgkg, Nell2, and Calb2), and three genes into transport and establishment and localization cluster (Ttr, Rab5b, and Tomm22) (Table 7).

Statistically significant $(p<0.05)$ over-expressed terms associated with the up- and downregulated genes were found in both strains subjected to CMS. Functional annotation was done in each strain on a list of up- and downregulated transcripts separately. In HA mice, CMS affected the upregulation of genes involved in, e.g., intracellular signaling, ion binding, neuropeptide hormone activity, and metabolism of cAMP and nucleotides (Fig. 4a). Downregulated genes were those involved in ion transport, reproductive and mating behavior, neuron differentiation and dendrite development, cell communication, regulation of insulin secretion and response to insulin stimulus, regulation of transport, homeostasis, focal adhesion, ion channel activity, or MAPK signaling pathway (Fig. 4b).

In LA mice, CMS affected the upregulation of genes involved in the activation of protein kinase $\mathrm{C}$, regulation of transcription, calcium ion binding, hormone binding, or coding elements of dendrites (Fig. 5a). Downregulated genes were involved in locomotory behavior, signal transduction and immunity processes, or long-term depression (Fig. 5b).

For more detailed data interpretation, we performed the functional clustering of DEGs. Functional clustering of DEGs between stressed vs. control animals revealed several functional groups of genes in each strain. Altogether, 11 main clusters were found for HA (Table 8) and 12 for LA (Table 9). Specific clusters for HA strain contain genes involved in regulation of hormone secretion/regulation of insulin secretion, ion binding, regulation of primary metabolic process/regulation of cAMP biosynthetic process, and cell junction/adherens junction. Specific clusters for LA strain contain genes involved in response to stress, dendrite/neuron projection, immune effector process/immune response, intracellular signaling cascade/GTPase regulator activity and cognition. Functional clustering revealed similar clusters in both lines despite containing different genes. Overlapping clusters in both strains were clusters such as signal transduction, response to stimulus, regulation of biological quality and homeostasis, cell differentiation, apoptosis and cell death, regulation of transcription and gene expression, and signal transducer/receptor activity. Clusters were identified in the list of the significantly upregulated and downregulated genes in non stressed vs. stressed animals. Tables 8 and 9 present significant functional clusters with differentially expressed genes and their expression values.

\section{Validation of Microarrays}

To confirm differential expression indicated by the microarray expression patterns, the quantitative real-time reverse transcription PCR was used (qPCR). qPCR were performed using aliquots of the non-pooled total RNA. Following genes were selected from the list of the significant functional clusters in each strain: Ttr, Drd1, Dgkg, Prkcb, VGluT1, Prlr, and Nts for HA strain, and

Table 5 Upregulated genes associated with the gene ontology (GO) molecular function terms $(p<0.05)$ in the prefrontal cortex of low analgesia (LA) mice

\begin{tabular}{llll}
\hline GO molecular function & Number of genes & EASE score & Genes \\
\hline Structural constituent of ribosome & 3 & 0.033 & MRPS18C, RPL6, RPS15A \\
\hline
\end{tabular}


Table 6 Common transcripts with overlapping changes in the prefrontal cortex of high (HA) and low (LA) analgesia mice followed chronic mild stress (CMS)

\begin{tabular}{|c|c|c|c|c|}
\hline Gene symbol & Definition & Expression & HA fold change & LA fold change \\
\hline $\operatorname{Ttr}$ & Transthyretin (Ttr) & $\uparrow$ & 6.09 & 2.54 \\
\hline Tomm22 & Translocase of outer mitochondrial membrane 22 & $\uparrow \downarrow$ & 2.75 & -2.18 \\
\hline $\mathrm{C} 1 \mathrm{q} 12$ & Complement component 1 , q subcomponent-like 2 & $\uparrow$ & 1.32 & 1.48 \\
\hline 1300006M19Rik & RIKEN cDNA 1300006 M19 gene & $\uparrow$ & 2.26 & 2.38 \\
\hline 0610009K11Rik & Mitochondrial ubiquitin ligase activator of NFKB 1 & $\uparrow \downarrow$ & 2.12 & -1.58 \\
\hline Wdr6 & WD repeat domain 6 (Wdr6) & $\uparrow$ & 1.97 & 1.56 \\
\hline Mtss 11 & Metastasis suppressor 1-like & $\uparrow$ & 1.45 & 1.55 \\
\hline ВC040774 & & $\uparrow$ & 2.46 & 2.20 \\
\hline ВC060632 & & $\uparrow$ & 1.86 & 1.65 \\
\hline Nell2 & Nel-like 2 homolog (chicken) (Nell2) & $\uparrow$ & 1.54 & 2.29 \\
\hline Calb2 & calbindin 2 (Calb2) & $\uparrow$ & 1.69 & 1.29 \\
\hline Rab5b & RAB5B, member RAS oncogene family (Rab5b) & $\uparrow$ & 1.58 & 2.36 \\
\hline Krt1-12 & Keratin complex 1, acidic, gene 12 (Krt1-12) & $\uparrow \downarrow$ & 1.61 & -1.37 \\
\hline Nnat & Neuronatin (Nnat), transcript variant 2 & $\uparrow$ & 1.50 & 1.83 \\
\hline Dgkg & Diacylglycerol kinase, gamma (Dgkg) & $\uparrow$ & 1.30 & 1.25 \\
\hline C630041L24Rik & RIKEN cDNA C630041L24 gene & $\uparrow$ & 1.28 & 1.35 \\
\hline Cntnap4 & Contactin-associated protein 4 (Cntnap4) & $\uparrow$ & 0.52 & 0.75 \\
\hline Ddx6 & DEAD (Asp-Glu-Ala-Asp) box polypeptide 6 & $\downarrow$ & -1.38 & -1.46 \\
\hline AI593442 & Mus musculus expressed sequence AI593442 & $\downarrow$ & -1.51 & -1.68 \\
\hline Rasd2 & RASD family, member 2 & $\downarrow$ & -1.73 & -1.64 \\
\hline Indo & Indoleamine-pyrrole 2,3 dioxygenase & $\downarrow$ & -2.19 & -1.89 \\
\hline Rgs9 & Regulator of G-protein signaling 9 (Rgs9) & $\downarrow$ & -2.35 & -2.31 \\
\hline Pigt & Phosphatidylinositol glycan, class T (Pigt) & $\downarrow$ & -3.22 & -1.25 \\
\hline
\end{tabular}

“个” upregulation, “ $\downarrow "$ downregulation

Ttr, Crhr1, Dgke, Grm5, Prkcc, Gpm6a, and Mog for LA strain. The expression patterns of the selected genes are shown in Fig. 6a, b. Similar trends in gene expression were shown as in the microarrays. Genes selected according to microarray analyses showed corresponding values with a high correlation. Correlation for the selected data points was $R=0.91 \quad(p<0.0001)$.

\section{Discussion}

Environmental factors and genes contribute to the manifestation of phenotype which, however, may occur or not. The proper activity of a complex organ such as the brain relies on precise temporal and spatial gene expression patterns. The phenotype is a result of a cascade of transcriptional events that finally triggers gene expression and determines the function of the particular brain structures. While a certain set of genes is constantly expressed to maintain the organ structure, a varying number of genes are regulated according to the metabolic demand of the surrounding organism. PFC is the brain region that is most sensitive to the detrimental effects of stress exposure. Abilities of PFC depend on proper neuronal network connections, which are highly sensitive to their neurochemical environment (Arnsten 2009). Since exposure to even a mild uncontrollable stress can rapidly impair PFC functions, which contribute to PFC deficits and structural changes in human and animals, a good understanding of the genetic control of chronic stress exposure will facilitate further progress in understanding the pathophysiology of stress. Gene expression level could thus be a biomarker and provide information, for example, for psychiatric diagnosis.

It is important to have animal models of stress response to understand the mechanisms that render individuals vulnerable. In this study, we have focused on the comparison of prefrontal cortex transcription profiles between naive and stressed inbred mice strains with different sensitivity to stress. Studies of differences in gene expression were carried out with $24 \mathrm{~K}$ oligonucleotide microarrays for genome-wide gene expression analysis and the real-time RT-PCR technique for microarray validation. To determine the physiological processes that are differentially 
Table 7 Clusters of overlapping transcripts determined by the DAVID v6.7 software $(p<0.05)$

\begin{tabular}{ll}
\hline Gene symbol & Definition \\
\hline Signal transduction/intracellular signaling cascade \\
Rab5b & RAB5B, member RAS oncogene family \\
Rasd2 & RASD family, member 2 \\
Cntnap4 & Contactin-associated protein-like 4 \\
Dgkg & Diacylglycerol kinase, gamma \\
Mtss11 & Metastasis suppressor 1-like \\
Rgs9 & Regulator of G-protein signaling 9 \\
Calcium ion binding/metal & ion binding/cation binding \\
Nell2 & NEL-like 2 (chicken) \\
Calb2 & Calbindin 2 \\
Dgkg & Diacylglycerol kinase, gamma \\
Transport/establishment of localization \\
Rab5b & RAB5B, member RAS oncogene family \\
Tomm22 & Translocase of outer mitochondrial \\
& membrane 22 homolog \\
Ttr & Transthyretin \\
Membrane part & Translocase of outer mitochondrial \\
Rab5b & membrane 22 homolog \\
Rasd2 & Regulator of G-protein signaling 9 9 \\
Calb2 & RASD family, member 2 \\
Cntnap4 & Calbindin 2 \\
AI593442 & Contactin-associated protein-like 4 \\
Pigt & Expressed sequence AI593442 \\
Tomm22 & biosynthesis \\
Rgs9 & \\
\hline &
\end{tabular}

regulated between strains, the DAVID 6.7 Functional Annotation Tool was used.

For validation of oligonucleotide chip data, we performed real-time RT-PCR with the same RNA samples that was used for the microarray experiments. Gapdh and Hprt1 were used as a reference. These genes were not regulated between HA and LA during stress procedure in our study and have been used successfully as a housekeeping control in previous study as well (Lisowski et al. 2011). Other housekeeping genes that have been proposed such as beta actin were found to be regulated in brain between strains and/or stressed vs. control mice. In this study, the average fold change of correlation between microarray and qRTPCR was $0.91(p<0.0001)$. Large-scale study of real-time RT-PCR and gene expression measurements with commercial oligonucleotide microarrays concluded that microarrays are invaluable discovery tools with acceptable reliability for genome-wide gene expression screening, though validation of putative changes in gene expression remains advisable (Wang et al. 2006).
Differences in Basal Gene Expression of HA Mice Compared to LA Mice

As a way of identifying stress-responsive candidate genes, we conducted gene expression profiling studies in the PFC of high (HA) and low (LA) swim stress-induced analgesia inbred mouse strains. The strains display robust differences in behavioral tests reflecting depression and in responses to different classes of antidepressants (desipramine, venlafaxine, and aminosenktide) (Błaszczyk et al. 2000; Juszczak et al. 2008a, b, 2006; Panocka et al. 1986a). Experimental models of SIA help in identifying the fundamental mechanisms of stress response. The phenomenon that pain can be naturally suppressed leads to speculation that manipulation of the mechanisms of SIA could be a potential therapeutic target for stress- and anxiety-related disorders (Butler and Finn 2009). It may also be possible to utilize the expression of SIA as a predictor for development of psychological disorders (Meeus et al. 2008; Nishith et al. 2002; Pielsticker et al. 2005; Staud et al. 2003).

Identification of 193 differentially expressed genes between the strains supported by functional classification showed that selective breeding seriously affected frontal cortex development in aspect of structural changes such as neuron projection, neuron development, neuron differentiation, membrane organization, or dendrite development. SIA is mediated by activation of the descending inhibitory pain pathway that originates in neurons in higher brain regions such as the cortex. Neurons in the cortex also relay nociceptive information to the amygdala, hypothalamus, or directly to the periaqueductal grey. The PFC has also been implicated in the recall and extinction of fear-related memory of noxious stimuli (Hugues et al. 2004). Upregulation in the PFC of HA mice expression pattern of genes involved in calcium ion binding, lipid binding, diacyroglicerol binding, VEGF signaling, MAPK signaling, T cell receptor signaling, focal adhesion, or long-term potentiation suggests increased activation of neurons, leading to high analgesic phenotype and complex prefrontal cortex mechanisms of pain, stress, or fear.

Effects of Chronic Mild Stress on Gene Expression in HA and LA Mice

The chronic mild stress has been studied at the cellular level (Airan et al. 2007; Banasr and Duman 2007; Garcia-Garcia et al. 2009; Gronli et al. 2007; Jayatissa et al. 2008; WarnerSchmidt and Duman 2006). In addition to core symptoms of depression, such as long-lasting anhedonia (Elizalde et al. 2008), CMS induces neuroadaptive changes that could be addressing clinical findings with depressed patients (Frodl et al. 2008; Gould et al. 2007; Lucassen et al. 2006; Rajkowska 2000; Sanacora et al. 2004). Very little is known about the 
a
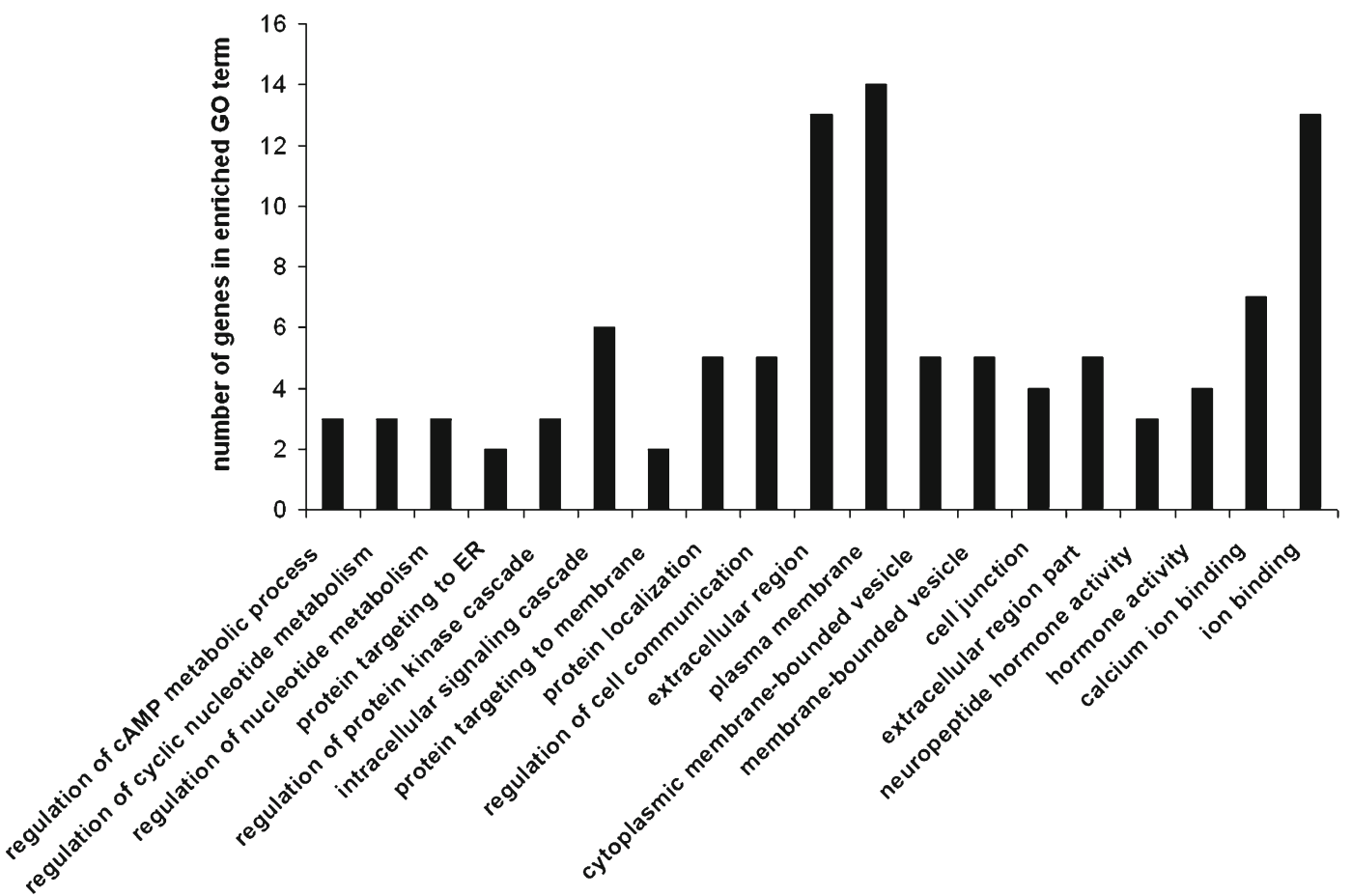

b
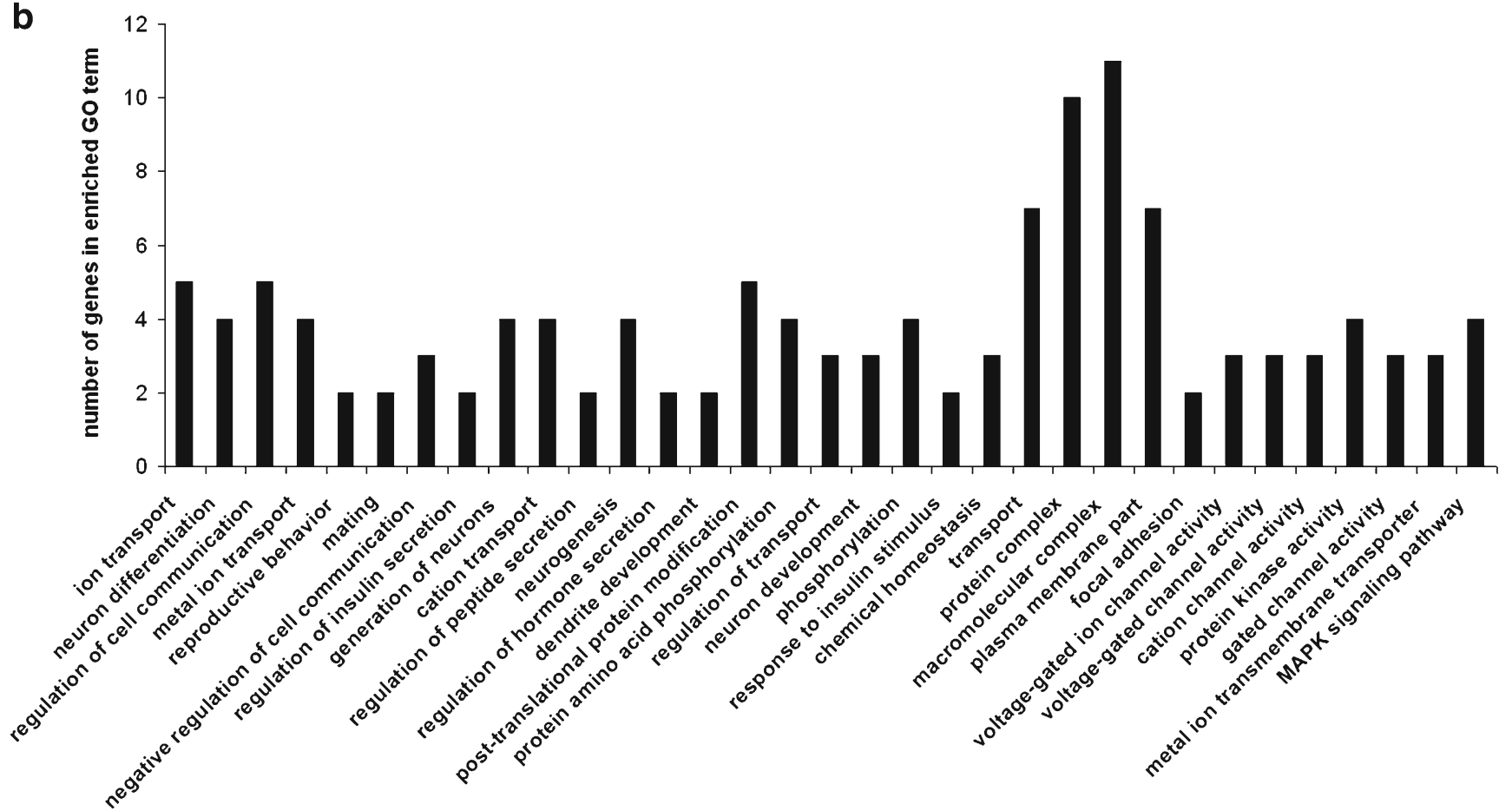

Fig. 4 Significantly enriched $(p<0.05)$ gene ontology $(\mathrm{GO})$ categories of genes affected by chronic mild stress (CMS) in the prefrontal cortex of high analgesia (HA) mice: a upregulated transcripts, and b

effects of chronic stress on transcriptome in the prefrontal cortex. Recent studies on primates demonstrate that social stress reduces the expression of many genes in the PFC that are involved in synaptic plasticity, cell cycle progression, and nuclear receptor signaling (Karssen et al. 2007). According to downregulated transcripts. GO categories shown in the figure consists of biological processes, molecular functions, cellular components, and biochemical pathways

Tordera (2011), CMS affected the regulation of 147 transcripts in a mouse CMS model, some of them involved in response to stress and oxidoreductase activity. Here, we aimed to identify in animals with different genetic background (HA CMS and LA CMS mice) specific gene expression profiles and common 
a
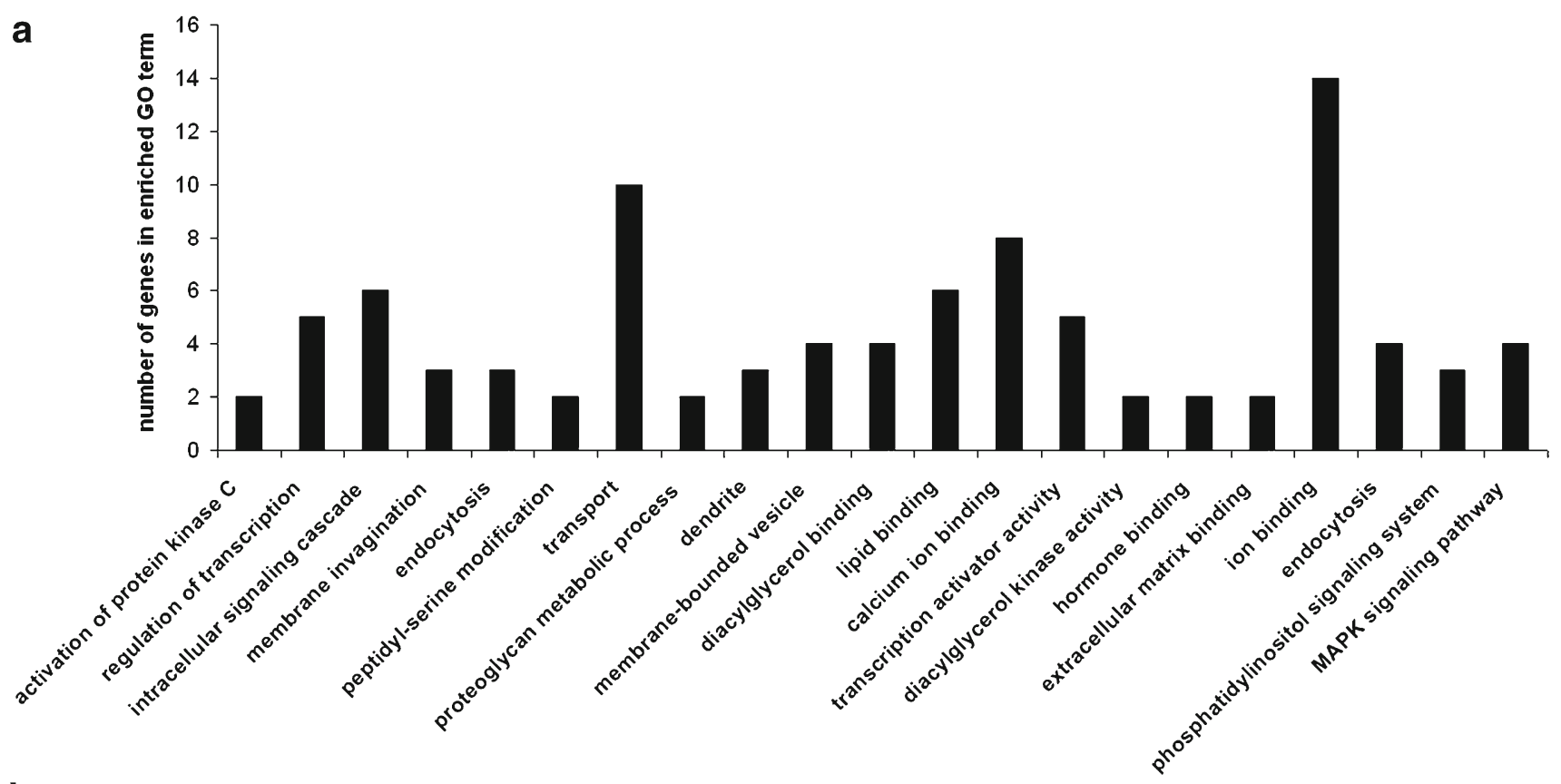

b

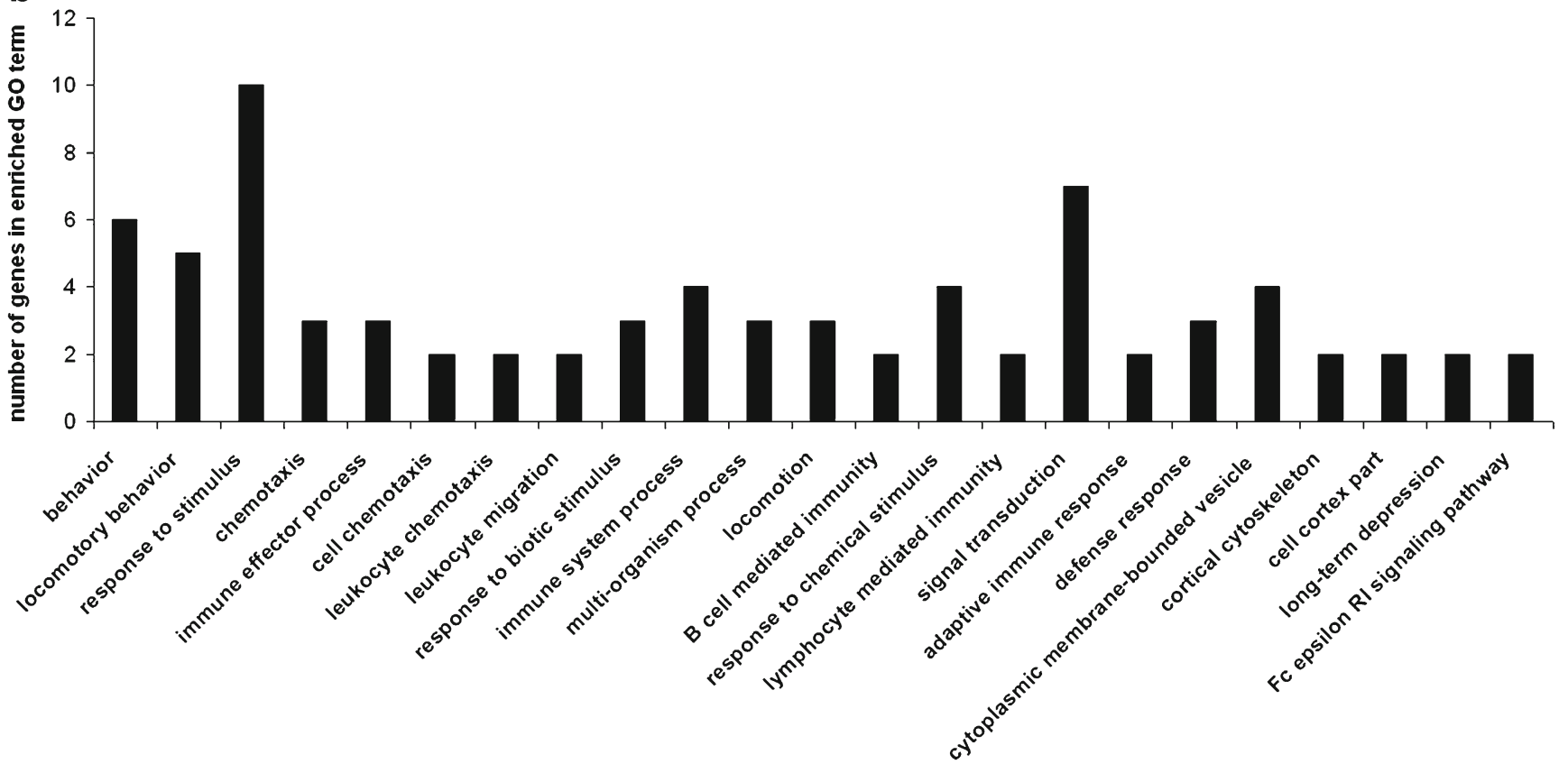

Fig. 5 Significantly enriched $(p<0.05)$ gene ontology $(\mathrm{GO})$ categories of genes affected by chronic mild stress (CMS) in the prefrontal cortex of low analgesia (LA) mice: a upregulated transcripts, and b

gene expression changes. We have identified genes similarly regulated by CMS in both strains. Overlapping genes with the same expression pattern in both mouse models are involved in coding elements of cell membrane part and are involved in signal transduction, calcium ion binding, and transport. We observed robust upregulation of Ttr gene coding transthyretin (TTR). Transthyretin is one of the three prealbumins: alpha-1antitrypsin, transthyretin, and orosomucoid. Transthyretin is a carrier protein and a major transporter of thyroid hormones downregulated transcripts. GO categories shown in the figure consists of biological processes, molecular functions, cellular components and biochemical pathways

and retinol in the plasma and cerebrospinal fluid (Landers et al. 2009). The diseases caused by mutations in TTR include amyloidotic polyneuropathy, euthyroid hyperthyroxinaemia, amyloidotic vitreous opacities, cardiomyopathy, oculoleptomeningeal amyloidosis, meningocerebrovascular amyloidosis, or carpal tunnel syndrome (Blevins et al. 2003; Garzuly et al. 1996; Jones et al. 1992; Murakami et al. 1994, 1992; Saraiva et al. 1992). Clinical features of defects in TTR include seizures, stroke-like episodes, dementia, and psychomotor 
Table 8 Clusters of genes determined by the DAVID v6.7 software $(p<0.05)$ affected by chronic mild stress $(\mathrm{CMS})$ in the prefrontal cortex of high analgesia (HA) mice

\begin{tabular}{|c|c|c|c|}
\hline Gene symboal & Gene name & Expression & Fold Change \\
\hline \multicolumn{4}{|c|}{ Regulation of cell communication/regulation of signal transduction } \\
\hline Bat2 & HLA-B-associated transcript 2 & $\uparrow$ & 1.48 \\
\hline Acvr1c & Activin A receptor, type IC & $\downarrow$ & -2.10 \\
\hline Bai1 & Brain-specific angiogenesis inhibitor 1 & $\uparrow$ & 1.61 \\
\hline Dkk3 & Dickkopf homolog 3 (Xenopus laevis) & $\downarrow$ & -1.48 \\
\hline Drd1a & Dopamine receptor D1A & $\downarrow$ & -1.28 \\
\hline Mtap1b & Microtubule-associated protein 1B & $\downarrow$ & -1.45 \\
\hline Palm & Paralemmin & $\uparrow$ & 1.34 \\
\hline $\mathrm{Cbx} 3$ & Predicted gene 6917 ; similar to chromobox homolog 3 & $\downarrow$ & -2.17 \\
\hline Rgs9 & Regulator of G-protein signaling 9 & $\downarrow$ & -2.35 \\
\hline Sostdc1 & Sclerostin domain containing 1 & $\uparrow$ & 1.50 \\
\hline Srp9 & Signal recognition particle 9 & $\uparrow$ & 2.49 \\
\hline Timp2 & Tissue inhibitor of metalloproteinase 2 & $\uparrow$ & 1.55 \\
\hline \multicolumn{4}{|c|}{ Regulation of hormone secretion/regulation of insulin secretion } \\
\hline Bat2 & HLA-B-associated transcript 2 & $\uparrow$ & 1.48 \\
\hline Acvr1c & Activin A receptor, type IC & $\downarrow$ & -2.10 \\
\hline Avp & Arginine vasopressin & $\uparrow$ & 3.67 \\
\hline Drd1a & Dopamine receptor D1A & $\downarrow$ & -1.28 \\
\hline Il12a & Interleukin $12 \mathrm{a}$ & $\downarrow$ & -1.32 \\
\hline $\mathrm{K} 1$ & Klotho & $\downarrow$ & -2.20 \\
\hline Nnat & Neuronatin & $\uparrow$ & 1.50 \\
\hline Pfkm & Phosphofructokinase, muscle & $\downarrow$ & -1.83 \\
\hline \multicolumn{4}{|l|}{ Ion binding } \\
\hline $\operatorname{Arl3}$ & ADP-ribosylation factor-like 3 & $\uparrow$ & 3.10 \\
\hline Lasp1 & LIM and SH3 protein 1 & $\downarrow$ & -1.85 \\
\hline Nell2 & NEL-like 2 (chicken) & $\uparrow$ & 1.70 \\
\hline Acvr1c & Activin A receptor, type IC & $\downarrow$ & -2.10 \\
\hline Calb2 & Calbindin 2 & $\uparrow$ & 1.69 \\
\hline Cacna2d1 & Calcium channel, voltage-dependent, alpha2/delta subunit 1 & $\downarrow$ & -1.38 \\
\hline Calml4 & Calmodulin-like 4 & $\uparrow$ & 1.52 \\
\hline Clic6 & Chloride intracellular channel 6 & $\uparrow$ & 1.77 \\
\hline Dgkg & Diacylglycerol kinase, gamma & $\uparrow$ & 1.30 \\
\hline Hpcal4 & Hippocalcin-like 4 & $\uparrow$ & 1.22 \\
\hline $\mathrm{K} 1$ & Klotho & $\uparrow$ & 1.92 \\
\hline Mmp17 & Matrix metallopeptidase 17 & $\downarrow$ & -1.26 \\
\hline Myl4 & Myosin, light polypeptide 4 & $\downarrow$ & -1.50 \\
\hline Pfkm & Phosphofructokinase, muscle & $\downarrow$ & -1.83 \\
\hline Kenb1 & Potassium voltage gated channel, Shab-related subfamily & $\downarrow$ & -1.98 \\
\hline Kenh1 & Potassium voltage-gated channel, subfamily H (eag-related) & $\downarrow$ & -1.85 \\
\hline Pnck & Pregnancy upregulated non-ubiquitously expressed $\mathrm{CaM}$ kinase & $\uparrow$ & 1.40 \\
\hline Prkcb & Protein kinase $\mathrm{C}$, beta & $\downarrow$ & -0.65 \\
\hline Sparc & Secreted acidic cysteine rich glycoprotein & $\uparrow$ & 1.54 \\
\hline Slc17a7 & Solute carrier family 17 & $\uparrow$ & 1.22 \\
\hline Zfp423 & Zinc finger protein 423 ; similar to mKIAA0760 protein & $\uparrow$ & 1.42 \\
\hline Zcchc12 & Zinc finger, $\mathrm{CCHC}$ domain containing 12 & $\uparrow$ & 1.89 \\
\hline \multicolumn{4}{|c|}{ Regulation of primary metabolic process/regulation of cAMP biosynthetic process } \\
\hline Avp & Arginine vasopressin & $\uparrow$ & 3.67 \\
\hline Drdla & Dopamine receptor D1A & $\downarrow$ & -1.28 \\
\hline
\end{tabular}


Table 8 (continued)

\begin{tabular}{|c|c|c|c|}
\hline Gene symboal & Gene name & Expression & Fold Change \\
\hline Palm & Paralemmin & $\uparrow$ & 1.34 \\
\hline Kenh1 & Potassium voltage-gated channel, subfamily $\mathrm{H}$ & $\downarrow$ & -1.85 \\
\hline $\mathrm{Cbx} 3$ & Predicted gene 6917 ; similar to chromobox homolog 3 & $\downarrow$ & -2.17 \\
\hline Rbbp4 & Retinoblastoma binding protein 4 & $\downarrow$ & -1.87 \\
\hline Srp9 & Signal recognition particle 9 & $\uparrow$ & 2.49 \\
\hline Timp2 & Tissue inhibitor of metalloproteinase 2 & $\uparrow$ & 1.55 \\
\hline Zfp423 & Zinc finger protein 423 ; similar to mKIAA0760 protein & $\uparrow$ & 1.42 \\
\hline Zcchc12 & Zinc finger, $\mathrm{CCHC}$ domain containing 12 & $\uparrow$ & 1.89 \\
\hline \multicolumn{4}{|c|}{ Cell junction/adherens junction } \\
\hline Lasp1 & LIM and SH3 protein 1 & $\downarrow$ & -1.85 \\
\hline Calb2 & Calbindin 2 & $\uparrow$ & 1.69 \\
\hline Cbln 1 & Cerebellin 1 precursor protein; similar to precerebellin-1 & $\downarrow$ & -2.06 \\
\hline Pak1 & p21 protein $(\mathrm{Cdc} 42 / \mathrm{Rac})$-activated kinase 1 & $\downarrow$ & -2.06 \\
\hline Pkp2 & Plakophilin 2 & $\uparrow$ & 1.26 \\
\hline Slc17a7 & Solute carrier family 17 & $\uparrow$ & 1.22 \\
\hline \multicolumn{4}{|c|}{ Response to endogenous stimulus/response to hormone stimulus } \\
\hline Bat2 & HLA-B-associated transcript 2 & $\uparrow$ & 1.48 \\
\hline Bat5 & HLA-B-associated transcript 5 & $\uparrow$ & 3.36 \\
\hline Rasd2 & RASD family, member 2 & $\downarrow$ & -1.73 \\
\hline Acvr1c & Activin A receptor, type IC & $\downarrow$ & -2.10 \\
\hline Avp & Arginine vasopressin & $\uparrow$ & 3.67 \\
\hline Drdla & Dopamine receptor D1A & $\downarrow$ & -1.28 \\
\hline $\mathrm{H} 2-\mathrm{L}$ & Histocompatibility 2, D region; histocompatibility 2 & $\uparrow$ & 2.56 \\
\hline Il12a & Interleukin $12 \mathrm{a}$ & $\downarrow$ & -1.32 \\
\hline Nnat & Neuronatin & $\uparrow$ & 1.50 \\
\hline Ppp1r1b & Protein phosphatase 1, regulatory (inhibitor) subunit 1B & $\downarrow$ & -1.68 \\
\hline Ptpra & Protein tyrosine phosphatase, receptor type, A & $\downarrow$ & -1.78 \\
\hline Rgs9 & Regulator of G-protein signaling 9 & $\downarrow$ & -2.35 \\
\hline Slc17a7 & Solute carrier family 17 & $\uparrow$ & 1.22 \\
\hline $\operatorname{Trh}$ & Thyrotropin-releasing hormone & $\uparrow$ & 1.91 \\
\hline \multicolumn{4}{|c|}{ Homeostatic process/regulation of biological quality } \\
\hline Avp & Arginine vasopressin & $\uparrow$ & 3.67 \\
\hline Drd1a & Dopamine receptor D1A & $\downarrow$ & -1.28 \\
\hline Nts & Neurotensin & $\uparrow$ & 1.58 \\
\hline Palm & Paralemmin & $\uparrow$ & 1.34 \\
\hline Pfkm & Phosphofructokinase, muscle & $\downarrow$ & -1.83 \\
\hline Prkcb & Protein kinase $\mathrm{C}$, beta & $\downarrow$ & -0.65 \\
\hline Ppp1r1b & Protein phosphatase 1 , regulatory (inhibitor) subunit 1B & $\downarrow$ & -1.68 \\
\hline Slc17a7 & Solute carrier family 17 & $\uparrow$ & 1.22 \\
\hline \multicolumn{4}{|c|}{ Generation of neurons/neurogenesis/neuron differentiation } \\
\hline Acvr1c & Activin A receptor, type IC & $\downarrow$ & -2.10 \\
\hline Dkk3 & Dickkopf homolog 3 (Xenopus laevis) & $\downarrow$ & -1.48 \\
\hline Drdla & Dopamine receptor D1A & $\downarrow$ & -1.28 \\
\hline $\mathrm{K} 1$ & Klotho & $\uparrow$ & 1.92 \\
\hline Mtap1b & Microtubule-associated protein 1B & $\downarrow$ & -1.45 \\
\hline Nnat & Neuronatin & $\uparrow$ & 1.50 \\
\hline Pak1 & p21 protein $(\mathrm{Cdc} 42 / \mathrm{Rac})$-activated kinase 1 & $\downarrow$ & -2.06 \\
\hline Pigt & Phosphatidylinositol glycan anchor biosynthesis, class $\mathrm{T}$ & $\downarrow$ & -3.22 \\
\hline Pkp2 & Plakophilin 2 & $\uparrow$ & 1.26 \\
\hline
\end{tabular}


Table 8 (continued)

\begin{tabular}{|c|c|c|c|}
\hline Gene symboal & Gene name & Expression & Fold Change \\
\hline Prlr & Prolactin receptor & $\uparrow$ & 1.62 \\
\hline Sostdc 1 & Sclerostin domain containing 1 & $\uparrow$ & 1.50 \\
\hline Timp2 & Tissue inhibitor of metalloproteinase 2 & $\uparrow$ & 1.55 \\
\hline Zfp423 & Zinc finger protein 423 ; similar to mKIAA0760 protein & $\uparrow$ & 1.42 \\
\hline \multicolumn{4}{|c|}{ Apoptosis/cell death } \\
\hline Bat2 & HLA-B-associated transcript 2 & $\uparrow$ & 1.48 \\
\hline Acvr1c & Activin A receptor, type IC & $\downarrow$ & -2.10 \\
\hline Pigt & Phosphatidylinositol glycan anchor biosynthesis, class $\mathrm{T}$ & $\downarrow$ & -3.22 \\
\hline \multicolumn{4}{|c|}{ Regulation of gene expression/regulation of transcription } \\
\hline Kcnh1 & Potassium voltage-gated channel, subfamily $\mathrm{H}$ & $\downarrow$ & -1.85 \\
\hline $\mathrm{Cbx} 3$ & Predicted gene 6917 ; similar to chromobox homolog 3 & $\downarrow$ & -2.17 \\
\hline Rbbp4 & Retinoblastoma binding protein 4 & $\downarrow$ & -1.87 \\
\hline Srp9 & Signal recognition particle 9 & $\uparrow$ & 2.49 \\
\hline Zfp423 & Zinc finger protein 423 ; similar to mKIAA0760 protein & $\uparrow$ & 1.42 \\
\hline Zcchc12 & Zinc finger, $\mathrm{CCHC}$ domain containing 12 & $\uparrow$ & 1.89 \\
\hline \multicolumn{4}{|c|}{ Signal transducer activity/receptor activity } \\
\hline Acvr1c & Activin A receptor, type IC & $\downarrow$ & -2.10 \\
\hline Bai1 & Brain-specific angiogenesis inhibitor 1 & $\uparrow$ & 1.61 \\
\hline Drd1a & Dopamine receptor D1A & $\downarrow$ & -1.28 \\
\hline Folr1 & Folate receptor 1 (adult) & $\uparrow$ & 1.23 \\
\hline Igsf1 & Immunoglobulin superfamily, member 1 & $\uparrow$ & 2.09 \\
\hline Kenh1 & Potassium voltage-gated channel, subfamily $\mathrm{H}$ & $\downarrow$ & -1.85 \\
\hline Tomm 22 & Predicted gene 12906; predicted gene 7250 & $\uparrow$ & 2.75 \\
\hline Prlr & Prolactin receptor & $\uparrow$ & 1.62 \\
\hline Ptpra & Protein tyrosine phosphatase, receptor type, A & $\downarrow$ & -1.78 \\
\hline Rgs9 & Regulator of G-protein signaling 9 & $\downarrow$ & -2.35 \\
\hline
\end{tabular}

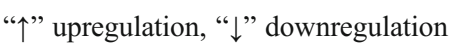

deterioration. The absence of TTR protein in TTR-null mice is associated with increased exploratory activity and reduced depression-like behavior (Sousa et al. 2004). Cell cultures incubated with TTR oligomers were proven to induce cytotoxicity by $\mathrm{Ca}^{2+}$ efflux from the endoplasmic reticulum (Teixeira et al. 2006). Moreover, recent observation conducted by Andrus (2012) classified Ttr to the set of genes whose hippocampal or amygdalar expression patterns were altered by chronic stress in four rat strains represent a generalizable molecular response to chronic stress. Taken together, we observed stress-associated significant cortical upregulation of Ttr and calcium ion binding genes (Nell2, Calb2, Dgkg) in both high and low analgesia mouse strains.

Given the genetic heterogeneity, it is likely that not all the subjects will show identical changes in all genes. We found that an individual's genetic make-up does make a serious difference in how the individual, at the gene expression level, responds to stress. Functional clustering revealed seven statistically significant overlapping groups of differentially expressed genes between control and stressed animals.
Common clusters, in both strains, included genes involved in behavior, signal transduction, response to hormone stimulus, homeostasis, neuron differentiation, neurogenesis, and apoptosis. The HA strain-specific groups of genes were involved in regulation of insulin secretion, cAMP biosynthetic process and cell junction. The LA strain groups of genes were connected with response to stress, dendrite and neuron projection, immune response, GTP-ase activity, and cognition.

Exposure to chronic stress leads to extensive alterations in the architecture of PFC including loss of dendritic material (Brown et al. 2005). Whereas structural changes in the hippocampus require several weeks of stress exposure, dendrites in the PFC begin to change after 1 week of stress or possibly even a single exposure (Brown et al. 2005; Izquierdo et al. 2006; McEwen 2004). The signaling mechanisms that underlie these changes in the PFC are just beginning to be studied. Each member of the PKC family has a specific expression profile and is believed to play distinct roles in cells. Protein kinase $\mathrm{C}$ gamma type is 
Table 9 Clusters of genes determined by the DAVID v6.7 software $(p<0.05)$ affected by chronic mild stress $(\mathrm{CMS})$ in the prefrontal cortex of low analgesia (LA) mice

\begin{tabular}{|c|c|c|c|}
\hline Gene symbol & Gene name & Expression & Fold change \\
\hline \multicolumn{4}{|c|}{ Signal transduction } \\
\hline Fcerlg & Fc receptor, IgE, high affinity I, gamma polypeptide & $\downarrow$ & -2.66 \\
\hline Gpr88 & G-protein coupled receptor 88 & $\downarrow$ & -1.23 \\
\hline Rab5b & RAB5B, member RAS oncogene family & $\uparrow$ & 2.36 \\
\hline Rasgrp1 & RAS guanyl-releasing protein 1 & $\uparrow$ & 1.31 \\
\hline Rasd2 & RASD family, member 2 & $\downarrow$ & -1.64 \\
\hline Cntnap4 & Contactin-associated protein-like 4 & $\uparrow$ & 0.75 \\
\hline Crhr1 & Corticotropin-releasing hormone receptor 1 & $\downarrow$ & -1.76 \\
\hline Dgke & Diacylglycerol kinase, epsilon & $\uparrow$ & 1.66 \\
\hline Dgkg & Diacylglycerol kinase, gamma & $\uparrow$ & 1.25 \\
\hline Grm5 & Glutamate receptor, metabotropic 5 & $\downarrow$ & -0.95 \\
\hline Gdi1 & Guanosine diphosphate (GDP) dissociation inhibitor 1 & $\uparrow$ & 1.99 \\
\hline Matk & Megakaryocyte-associated tyrosine kinase & $\downarrow$ & -1.53 \\
\hline Prkcc & Protein kinase $\mathrm{C}$, gamma & $\uparrow$ & 2.54 \\
\hline Rgs9 & Regulator of G-protein signaling 9 & $\downarrow$ & -2.31 \\
\hline Spock2 & Sparc/osteonectin, cwcv and kazal-like domains proteoglycan 2 & $\uparrow$ & 1.44 \\
\hline \multicolumn{4}{|c|}{ Response to stress } \\
\hline Fcer1g & Fc receptor, IgE, high affinity I, gamma polypeptide & $\downarrow$ & -2.66 \\
\hline Rasd2 & RASD family, member 2 & $\downarrow$ & -1.64 \\
\hline S100a8 & S100 calcium binding protein A8 (calgranulin A) & $\downarrow$ & -3.78 \\
\hline S100a9 & S100 calcium binding protein A9 (calgranulin B) & $\downarrow$ & -3.32 \\
\hline Capn2 & Calpain 2 & $\uparrow$ & 3.76 \\
\hline Camp & Cathelicidin antimicrobial peptide & $\downarrow$ & -1.72 \\
\hline Crhr1 & Corticotrophin-releasing hormone receptor 1 & $\downarrow$ & -1.76 \\
\hline Grm5 & Glutamate receptor, metabotropic 5 & $\downarrow$ & -0.95 \\
\hline Mt3 & Metallothionein 3 & $\uparrow$ & 1.89 \\
\hline Mpo & Myeloperoxidase & $\downarrow$ & -1.85 \\
\hline Nnat & Neuronatin & $\uparrow$ & 1.83 \\
\hline Igh-VJ558 & Predicted gene 5353; immunoglobulin heavy chain (J558 family) & $\downarrow$ & -1.63 \\
\hline Prkcc & Protein kinase $\mathrm{C}$, gamma & $\uparrow$ & 2.54 \\
\hline Rgs9 & Regulator of G-protein signaling 9 & $\downarrow$ & -2.31 \\
\hline \multicolumn{4}{|c|}{ Dendrite/neuron projection } \\
\hline Crmp1 & Collapsin response mediator protein 1 & $\uparrow$ & 1.36 \\
\hline Cntnap4 & Contactin-associated protein-like 4 & $\uparrow$ & 0.75 \\
\hline Prkcc & Protein kinase $\mathrm{C}$, gamma & $\uparrow$ & 2.54 \\
\hline \multicolumn{4}{|c|}{ Immune effector process/immune response } \\
\hline Atp6v0a1 & ATPase, $\mathrm{H}+$ transporting, lysosomal V0 subunit A1 & $\uparrow$ & 1.62 \\
\hline Fcer1g & Fc receptor, IgE, high affinity I, gamma polypeptide & $\downarrow$ & -2.66 \\
\hline S100a9 & S100 calcium binding protein A9 (calgranulin B) & $\downarrow$ & -3.32 \\
\hline Mpo & Myeloperoxidase & $\downarrow$ & -1.85 \\
\hline Igh-VJ558 & Predicted gene 5353; immunoglobulin heavy chain (J558 family) & $\downarrow$ & -1.63 \\
\hline \multicolumn{4}{|c|}{ Intracellular signaling cascade/GTPase regulator activity } \\
\hline Rab5b & RAB5B, member RAS oncogene family & $\uparrow$ & 2.36 \\
\hline Rasgrp1 & RAS guanyl-releasing protein 1 & $\uparrow$ & 1.31 \\
\hline $\operatorname{Rasd} 2$ & RASD family, member 2 & $\downarrow$ & -1.64 \\
\hline Dgke & Diacylglycerol kinase, epsilon & $\uparrow$ & 1.66 \\
\hline Dgkg & Diacylglycerol kinase, gamma & $\uparrow$ & 1.25 \\
\hline Gdi1 & Guanosine diphosphate (GDP) dissociation inhibitor 1 & $\uparrow$ & 1.99 \\
\hline
\end{tabular}


Table 9 (continued)

\begin{tabular}{|c|c|c|c|}
\hline Gene symbol & Gene name & Expression & Fold change \\
\hline Prkcc & Protein kinase $\mathrm{C}$, gamma & $\uparrow$ & 2.54 \\
\hline Rgs9 & Regulator of G-protein signaling 9 & $\downarrow$ & -2.31 \\
\hline \multicolumn{4}{|c|}{ Behavior/response to external stimulus } \\
\hline Fcer1g & Fc receptor, IgE, high affinity I, gamma polypeptide & $\downarrow$ & -2.66 \\
\hline Rasd2 & RASD family, member 2 & $\downarrow$ & -1.64 \\
\hline S100a8 & S100 calcium binding protein A8 (calgranulin A) & $\downarrow$ & -3.78 \\
\hline S100a9 & S100 calcium binding protein A9 (calgranulin B) & $\downarrow$ & -3.32 \\
\hline Crhr1 & Corticotrophin-releasing hormone receptor 1 & $\downarrow$ & -1.76 \\
\hline Grm5 & Glutamate receptor, metabotropic 5 & $\downarrow$ & -0.95 \\
\hline Prkcc & Protein kinase $\mathrm{C}$, gamma & $\uparrow$ & 2.54 \\
\hline \multicolumn{4}{|c|}{ Ion homeostasis/regulation of biological quality } \\
\hline Crym & Crystallin, mu & $\uparrow$ & 1.85 \\
\hline Grm5 & Glutamate receptor, metabotropic 5 & $\downarrow$ & -0.95 \\
\hline Ltf & Lactotransferrin & $\downarrow$ & -2.59 \\
\hline Mt3 & Metallothionein 3 & $\uparrow$ & 1.89 \\
\hline Sepw1 & Selenoprotein $\mathrm{W}$, muscle 1 & $\uparrow$ & 1.39 \\
\hline Slc26a4 & Solute carrier family 26 , member 4 & $\uparrow$ & 1.32 \\
\hline \multicolumn{4}{|c|}{ Nervous system development/cell differentiation } \\
\hline Atp6v0a1 & ATPase, $\mathrm{H}+$ transporting, lysosomal V0 subunit A1 & $\uparrow$ & 1.62 \\
\hline Capn2 & Calpain 2 & $\uparrow$ & 3.76 \\
\hline Grm5 & Glutamate receptor, metabotropic 5 & $\downarrow$ & -0.95 \\
\hline Kif3a & Kinesin family member $3 \mathrm{~A}$ & $\downarrow$ & -1.97 \\
\hline Lbh & Limb-bud and heart & $\uparrow$ & 1.50 \\
\hline Mt3 & Metallothionein 3 & $\uparrow$ & 1.89 \\
\hline Mog & Myelin oligodendrocyte glycoprotein & $\uparrow$ & 1.37 \\
\hline Nnat & Neuronatin & $\uparrow$ & 1.83 \\
\hline Nfib & Nuclear factor I/B & $\uparrow$ & 1.37 \\
\hline Pigt & Phosphatidylinositol glycan anchor biosynthesis, class $\mathrm{T}$ & $\downarrow$ & -1.25 \\
\hline Prkcc & Protein kinase $\mathrm{C}$, gamma & $\uparrow$ & 2.54 \\
\hline Rgs9 & Regulator of G-protein signaling 9 & $\downarrow$ & -2.31 \\
\hline Slc26a4 & Solute carrier family 26 , member 4 & $\uparrow$ & 1.32 \\
\hline Thra & Thyroid hormone receptor alpha; similar to thyroid hormone receptor & $\uparrow$ & 1.31 \\
\hline \multicolumn{4}{|c|}{ Regulation of apoptosis/regulation of programmed cell death } \\
\hline Fcer1g & Fc receptor, IgE, high affinity I, gamma polypeptide & $\downarrow$ & -2.66 \\
\hline Eef1a2 & Eukaryotic translation elongation factor 1 alpha 2 & $\uparrow$ & 1.90 \\
\hline Mal & Myelin and lymphocyte protein, T-cell differentiation protein & $\uparrow$ & 1.37 \\
\hline \multicolumn{4}{|c|}{ Regulation of transcription/regulation of gene expression } \\
\hline Atp6v0a1 & ATPase, $\mathrm{H}+$ transporting, lysosomal V0 subunit A1 & $\uparrow$ & 1.62 \\
\hline Atf4 & Activating transcription factor 4 & $\uparrow$ & 1.45 \\
\hline Brms11 & Breast cancer metastasis-suppressor 1-like & $\uparrow$ & 1.33 \\
\hline Eefla2 & Eukaryotic translation elongation factor 1 alpha 2 & $\uparrow$ & 1.90 \\
\hline Lbh & Limb-bud and heart & $\uparrow$ & 1.50 \\
\hline Nfib & Nuclear factor I/B & $\uparrow$ & 1.37 \\
\hline Thra & Thyroid hormone receptor alpha; similar to thyroid hormone receptor & $\uparrow$ & 1.31 \\
\hline Zfp238 & Zinc finger protein 238 & $\uparrow$ & 1.81 \\
\hline \multicolumn{4}{|c|}{ Signal transducer activity/receptor activity/G-protein coupled receptor activity } \\
\hline Fcer1g & Fc receptor, IgE, high affinity I, gamma polypeptide & $\downarrow$ & -2.66 \\
\hline Gpr88 & G-protein coupled receptor 88 & $\downarrow$ & -1.23 \\
\hline Crhr1 & Corticotrophin-releasing hormone receptor 1 & $\downarrow$ & -1.76 \\
\hline
\end{tabular}


Table 9 (continued)

\begin{tabular}{|c|c|c|c|}
\hline Gene symbol & Gene name & Expression & Fold change \\
\hline Grm5 & Glutamate receptor, metabotropic 5 & $\downarrow$ & -0.95 \\
\hline Mog & Myelin oligodendrocyte glycoprotein & $\uparrow$ & 1.37 \\
\hline Tomm22 & Predicted gene 12906; predicted gene 7250 & $\downarrow$ & -2.18 \\
\hline Rgs9 & Regulator of G-protein signaling 9 & $\downarrow$ & -2.31 \\
\hline Thra & Thyroid hormone receptor alpha; similar to thyroid hormone receptor & $\uparrow$ & 1.31 \\
\hline \multicolumn{4}{|l|}{ Cognition } \\
\hline Grm5 & Glutamate receptor, metabotropic 5 & $\downarrow$ & -0.95 \\
\hline Prkcc & Protein kinase $\mathrm{C}$, gamma & $\uparrow$ & 2.54 \\
\hline Rgs9 & Regulator of G-protein signaling 9 & $\downarrow$ & -2.31 \\
\hline
\end{tabular}

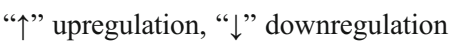

expressed solely in the brain and spinal cord and its localization is restricted to neurons. It has been demonstrated that several neuronal functions, including long-term potentiation (LTP) and long-term depression, specifically require this kinase. Knockout studies in mice also suggest that this kinase may be involved in neuropathic pain development (Malmberg et al. 1997). In our study, we have found that CMS decreased transcription of protein kinase $\mathrm{C}$, beta (Prkcc) in HA mice and increased protein kinase $\mathrm{C}$, gamma (Prkcg) in LA. Glucocorticoid release during stress could potentiate stress-signaling pathways through activation of PKC signaling (Han et al. 2002).

Chronic stress alters catecholamine pathways increasing noradrenergic innervation of the PFC although dopamine becomes depleted with severe chronic stress (Miner et al. 2006; Mizoguchi et al. 2000). Increased noradrenaline might lead to higher levels of PKC and cAMP signaling (Arnsten 2009). In LA mice, we have identified a cluster of genes downregulated by CMS which are involved in the cAMP biosynthetic process including the dopamine receptor D1A (Drdla). Moreover, PKCs require $\mathrm{Ca}^{2+}$, diacylglycerol (DAG), and a phospholipid such as phosphatidylserine for activation. According to this, another interesting group of genes identified in LA mice was intracellular signaling cascade/GTP-ase regulator activity cluster. This cluster, besides Prkcg consist of several upregulated genes in LA CMS animals including diacylglycerol kinases epsilon (Dgke) and gamma $(D g k g)$ involved in PKC signaling.

Stress-induced changes in dendritic morphology may be associated with upregulation of another two genes constituting dendrite/neurite projection gene cluster such as Crmpl (collapsin response mediator protein 1) and Cntnap4 (contactin associated protein-like 4). Crmpl encodes a member of a family of cytosolic phosphoproteins expressed exclusively in the nervous system. Encoded protein is thought to be a part of the semaphorin signal transduction pathway implicated in semaphorin-induced growth cone collapse. CRMP1 is necessary for signaling by class 3 semaphorins and subsequent remodeling of the cytoskeleton. Furthermore, it plays a role in axon guidance while Cntnap4 product belongs to the neurexin family, members of which function in the nervous system as cell adhesion molecules and receptors (Pasterkamp and Giger 2009; Yamashita et al. 2007).

Neural remodeling is a fundamental process by which the brain responds to environmental influences during stress. In PFC of stressed LA mice, we identified upregulation of three stress-responsive genes involved in myelin function: Gpm6a, Mal, and Mog. Gpm6a codes glycoprotein M6a which plays an important role in neurite outgrowth and synapse formation (Alfonso et al. 2005). This gene is downregulated in the hippocampus of both socially and physically stressed animals, and this effect can be reversed by antidepressant treatment (Alfonso et al. 2005). In our previous study, we found downregulation of Gpm6a in hippocampus of LA mice after CMS (Lisowski et al. 2011). GMP6A may play a role in the stress-induced hippocampal alterations that are found in psychiatric disorders (Boks et al. 2008). Mal encodes integral membrane protein belonging to the MAL family of proteolipids involved in myelin biogenesis and function. The product of Mog is a membrane protein MOG, expressed on the oligodendrocyte cell surface and the outermost surface of myelin sheaths. Downregulation of cortical Mog expression was found to be involved in schizophrenia and major depressive disorder (Aston et al. 2005; Martins-de-Souza et al. 2010). In the other hand, MOG is detectable in multiple sclerosis (MS) patients and is suspected to be involved in pathogenesis of MS (Stern and Keskin 2008). Upregulation of genes that encode structural components of myelin such as Gpma6, Mal, and Mog in PFC of LA mice could be an adaptive mechanism of stress response dependent on stress procedure duration or individual vulnerability.

CMS induces neuroadaptive changes that could address clinical findings in depressed patients (Frodl et al. 2008; Gould et al. 2007; Lucassen et al. 2006; Rajkowska 2000; 
a

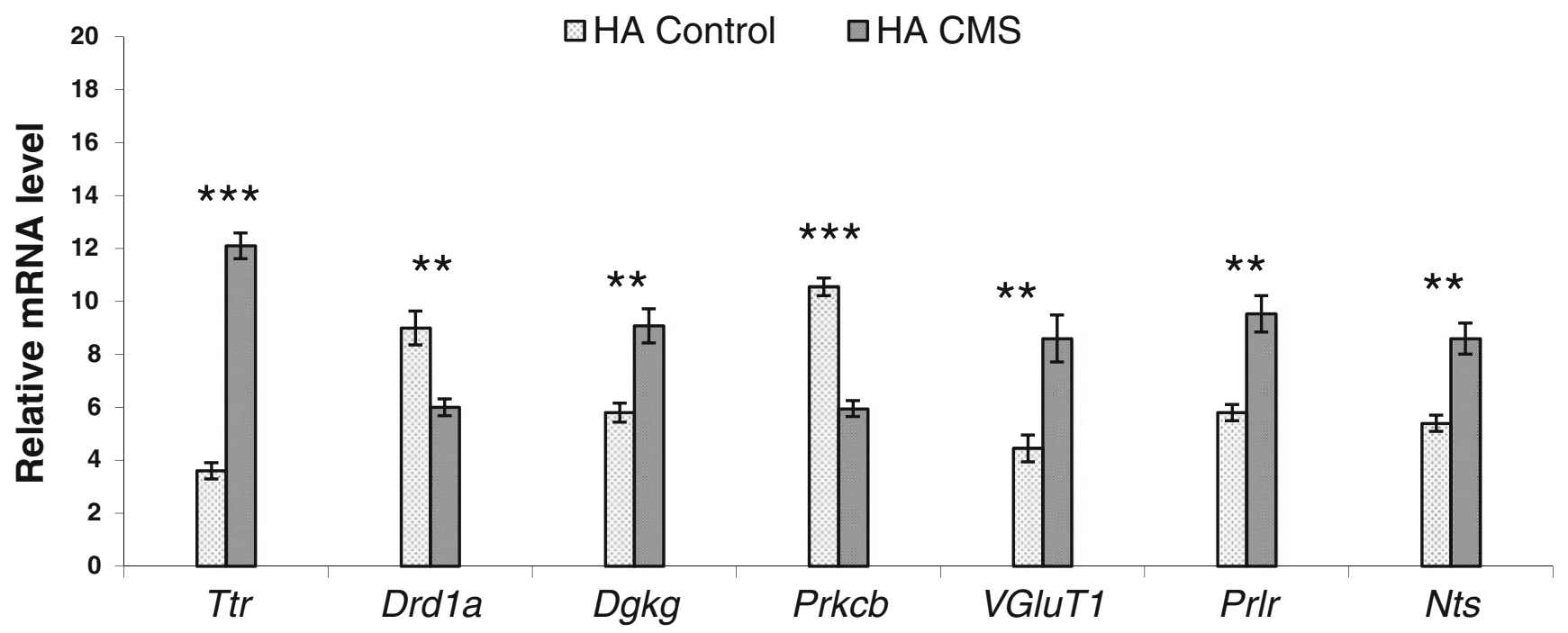

b

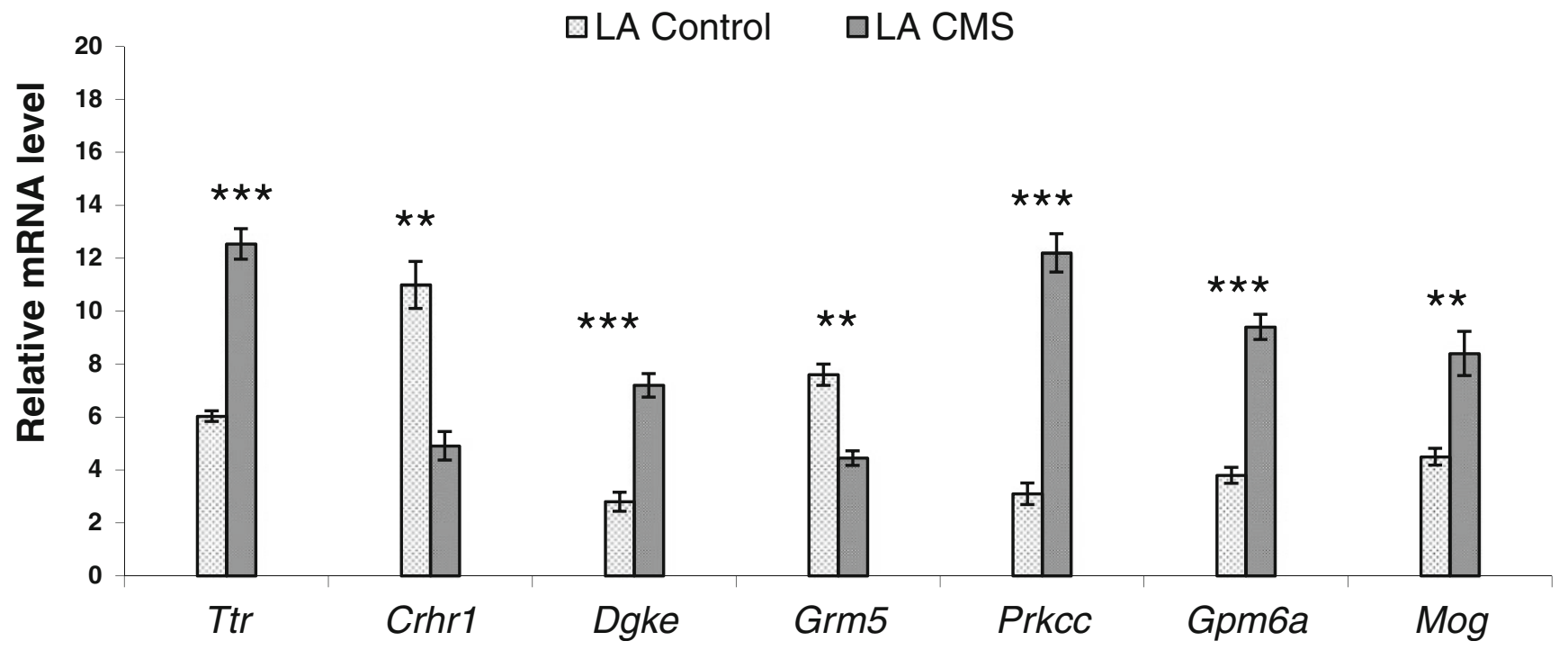

Fig. 6 Validation of expression of the selected genes by qPCR: a HA control vs. HA followed by CMS; b LA control vs. LA followed by CMS. Results are presented as means of relative mRNA levels in 15 individuals per experimental group; error indicators show \pm S.E.M. Values differ significantly at $* p<0.05, * * p<0.01$ or $* * * p<0.001$; qPCR values were normalized to geometric mean of the raw expression

Sanacora et al. 2004). Recent clinical (Uezato et al. 2009) and preclinical studies (Garcia-Garcia et al. 2009; Tordera et al. 2007) have linked decreased levels of the synaptic vesicle protein vesicular glutamate transporter 1 (VGLUT1) to depressive-like behavior. In addition, recent studies with heterozygous VGLUT1 knockout mice suggest that decreased VGLUT1 levels affects glutamate transmission and induces depressive-like behavior comorbid with anxiety and impaired recognition memory (Balschun et al. 2010; Tordera et al. 2007). On the other hand, in our study, we noticed upregulation of VGluT1 (also Slc17a7) in HA CMS data of two reference genes: Gapdh and Hprt1. Abbreviations: $q P C R$, quantitative real-time RT-PCR; $H A$, high analgesia mice; $L A$, low analgesia mice; $C M S$, chronic mild stress; S.E.M., standard error of measurement or mean; Gapdh, glyceraldehyde-3-phosphate dehydrogenase; Hprt1, hypoxanthine phosphoribosyltransferase 1

mice and downregulation of metabotropic glutamate receptor 5 (Grm5) in LA CMS mice. Grm5 is a subtype of group I glutamate receptors, is highly expressed in limbic forebrain regions, and is thought to modulate anxiety-related processes. The blockade of Grm5 by specific antagonist 2-methyl6-(phenylethynyl) pyridine, reduce extracellular norepinephrine, the impact of which may contribute to their anxiolytic actions (Page et al. 2005). We suggest that the downregulation of Grm5 together with disregulation of other genes included in signal transduction and response to stress clusters of LA CMS mice and upregulation of VGluT1 could 
be a mechanism of adaptation to stress of stress resistant individuals. Moreover, upregulation of VGluT1 is according to our previous study in which we have observed significant upregulation of VGluT1 and VGluT2 mRNA in the hippocampus of LA mice after CMS procedure (Lisowski et al. 2011).

In HA mice, we observed significant upregulation of arginine vasopressin transcript $(A v p)$. Activation of the hypothalamic-pituitary-adrenal system by psychosocial stress is accompanied by an increase in peripheral plasma AVP levels in human study (Zimmermann et al. 2004). Repeated stress is known to induce an increased vasopressin (AVP) expression in paraventricular corticotrophinreleasing hormone $(\mathrm{CRH})$ neurons that is supposed to enhance the ACTH-releasing capacity of these cells. Acute immobilization produced a significant increase in the average AVP and CRF mRNA levels in the medial parvocellular subdivisions of the paraventricular nucleus (PVN) (Aubry et al. 1999). PVN AVP mRNA levels are more sensitive to glucocorticoid negative feedback than are the levels of CRH mRNA (Makino et al. 1995). In the brain as a whole, AVP acts on wide array of neurons. AVP might also modulate emotional memory and anxiety (Koob 2008). We suggest that in CMS, a robust increase in PFC of Avp mRNA level is a mechanism contributing to the maintenance of a HPA response after repeated stress. Besides hypothalamus and amygdala, the PFC excitatory actions of AVP released from cortical neurons may also contribute to the behavioral stress response.

In our previous study, we found that naïve HA mice display robust upregulation of tridecapeptide neurotensin (NT) receptor transcript (Nts2r) in hippocampus as compared to naïve LA mice (Lisowski et al. 2012). Recently, it became evident that NT is involved in responsiveness to both pain and stressful stimuli, suggesting that this neurotransmitter may be involved in the phenomenon of nonopioid SIA (Dobner 2005). The release of endogenous NT in response to stress requires the presence of NTS2 to stimulate corticotropin-releasing factor-induced elevation of plasma corticosterone (Lafrance et al. 2010). These data highlight the significance of NTS2 as a novel target for the treatment of pain and stress-related disorders. In the current study, we observed significant upregulation of neurotensin transcript (Nts) in HA mice after CMS procedure. This gene encodes a common precursor for two peptides, neuromedin $\mathrm{N}$ and neurotensin. Neurotensin is a secreted tridecapeptide, which is widely distributed throughout the central nervous system, and may function as a neurotransmitter or a neuromodulator. It may be involved in dopamine-associated pathophysiological events. Both, Nts and Drdla were clustered in group of genes involved in homeostatic process/regulation of biological quality in HA CMS mice. In addition to the role of NT in the regulation of nociceptive processing, there is accumulating evidence suggesting that NT is involved in hormonal, neural, and behavioral stress-related responses. NT turnover is also altered under physiological stress. Exposure to various stressors, such as immobilization or cold-water swim, induces an up-regulation of the NT precursor mRNA in several hypothalamic regions, including the medial preoptic area and the paraventricular nucleus (Ceccatelli and Orazzo 1993; Seta et al. 2001). Since there are also studies that provided the evidence for the involvement of NT in the development of neuropsychiatric disorders, we suggest that the involvement of NT in the regulation of the hypothalamo-pituitary-adrenal gland axis during chronic stress should be considered in the context of vulnerability phenotypes.

Among differentially expressed genes of response to stress cluster in LA CMS mice, we identified robust upregulation of calpain 2 (Capn2) and downregulation of corticotrophin-releasing hormone receptor $1(\mathrm{Crhrl})$. Calpains are a group of calcium-dependent protease that plays a significant role in synaptic plasticity, cell motility, and neurodegeneration (Liu et al. 2005; Wu and Lynch 2006). Calpain-mediated spectrin degradation has been implicated in dendritic spine changes associated with LTP induction (Lynch and Baudry 1984; Vanderklish and Bahr 2000; Vanderklish et al. 2000). In addition, calpain inhibitors block LTP induction in vitro and in vivo (Denny et al. 1990; Staubli et al. 1988). Despite the quite well-known physiological role of m-calpain in brain, it is not clear under which conditions m-calpain could be activated (Friedrich 2004); however, based on our data, the chronic stress-dependent upregulation of Capn2 in PFC is possible in vulnerable phenotypes.

PFC contains "hot spots" of receptors for key stress mediators such as $\beta 1$-adrenoceptors ( $\beta 1 \mathrm{R})$, CRH receptors (CRHR1, CRHR2), mineralocorticoid, and glucocorticoid receptors (MR, GR) (Joels and Baram 2009). In LA CMS mice, we observed downregulation of Crhrl that encodes a G-protein-coupled receptor that binds neuropeptides of the $\mathrm{CRH}$ family. Actions of stress-induced CRH release are mediated primarily through binding to CRHR1 while binding to CRHR2 exert effects at long timescale and might function to shut down the stress response (Bale et al. 2000; Coste et al. 2000; Muller et al. 2003). Quantity of Crhrl mRNA in rodent PFC in contrast to Crhr2 is high (Aguilera et al. 2004). Significant downregulation of Crhrl transcription suggests decreased CRH binding following chronic stress in PFC. It is likely that transcriptional regulatory mechanisms that permit rapid changes in Crhrl activity in PFC are important for adaptation of corticotroph responsiveness to continuous changes in physiological demands. In this regard, pituitary Crhrl mRNA levels decrease following glucocorticoid administration and recover only when circulating glucocorticoids decline below stress levels (Ochedalski et al. 1998). These findings suggest that the glucocorticoids contribute to the decrease in 
cortical Crhr1 mRNA during stress. The mechanism regulating PFC Crhrl mRNA levels during stress is likely to involve increased exposure of the cortical corticotroph to glucocorticoids, CRH and AVP.

Insulin plays a role in the structural responses of the brain to stressors. Lack of insulin causes a decrease in dentate gyrus neuron number and leads to increased remodeling of dendrites of CA3 neurons that is further accelerated by repeated restraint stress. Stress and hyperglycemia both increase oxidative stress in the brain and this is likely to contribute, over time, to impaired neural function in chronic stress and diabetes. In the present study, we found that in HA mice, genes involved in hormone secretion including insulin secretion genes were deregulated. Among them, we found upregulation of prolactin receptor (Prlr). Study showed that prolactin (PRL) is a neuromodulator of behavioral and neuroendocrine stress coping in the rat (Blume et al. 2009; Torner et al. 2001). Downregulation of brain prolactin receptors increased anxiety-related behavior demonstrating an anxiolytic effect of PRL acting at brain level (Torner et al. 2001). Furthermore stress-induced increase of corticotropin secretion was decreased after chronic intracerebroventricular infusion of PRL (Torner et al. 2001). Fujikawa (2004) showed that PRL levels increase in response to stress acting on the central nervous system and plays an important role in helping to protect against acute stress-induced hypocalcemia. Taken together, prolactin acting at brain level has to be considered as a novel regulator of stress response and HPA axis reactivity in PFC.

The data from the current study indicate that in addition to abnormalities related to neurons, communication in chronic stress may be altered due to functional changes in multiple components of signal transduction mechanisms. Significant numbers of differentially expressed genes in our mouse models displayed altered expression in humans with neurodegenerative diseases. Also of interest was the decreased expression of Drdla, Crhrl, Grm5. Its altered activity has been associated with various human neurological disorders including schizophrenia, Alzheimer's disease and Huntington's disease. Regulation may serve as an adaptive mechanism in response to prolonged stress, and may be relevant to chronic stress-induced depression in PFC region.

\section{Conclusions}

To summarize, transcriptional profiling revealed evidence of changes in cell systems that might contribute to structural and functional abnormalities in the prefrontal cortex in individuals with different genetic backgrounds. Further studies are necessary to confirm these findings and to determine how these changes in gene expression are switched at different time-points of chronic stress. In genetically predisposed individuals, an imbalance in control mechanisms of gene expression can introduce a bias towards stress-related brain disease after adverse experiences. New candidate genes that serve as biomarkers for the prediction of stressvulnerable phenotypes should continue to be tested. The relevance of our findings to human stress, depression, or anxiety is yet unclear; however, our animal model for chronic stress allowed insights into molecular processes. Further assessment of alterations in gene expression in brain regions are required to determine the possible role of stressful situation during an adaptation or habituation to repeated stress. In addition, pharmacological validation should be performed to confirm that drugs active in the treatment of anxiety or depression could reversed the stress-induced gene expression alteration. It should be noted that despite the identification of different genes in each mice strain, the exposure to stress caused a similar biological effect based on GO database enrichements. The study results show that many genetic factors, not one allele, determine how an individual responds to stress and stressful situation.

\section{Limitations}

The assessment of the possible chronic stress-related alterations in the PFC transcriptome may be relevant to the mechanisms involved in stress-induced neuropsychopathologies. Transcriptomic model reduces the biological complexity of stress response to the genetic level, whereas it should include genomic, epigenomic, and proteomic levels in the context of systems biology. Our CMS model assumes that cortical cells can modify metabolic functions related to animals' behavior. Another thing is that many metabolic or cell cycle-related genes were identified among the differentially expressed transcripts certainly points to the possibility that the observed expression patterns could be only indirectly related to distinct LA and HA mice phenotypes and may underline differences in other organs, e.g., endocrine system functions. We speculate that the selection for high and low SIA may be the basis of strain differences at the brain metabolic level. Genes are tested at one time point, often not based on a biological system, e.g., circadian genes and circadian rhythm. Thus, further studies are needed to determine how the transcriptomic profiles of particular brain structures distributing in particular time points of chronic stress to unravel the differences between adaptation and disease. Furthermore, development of mouse models where identified genes are either knocked-down or overactive and crossing them with models of, e.g., Alzheimer's disease, Parkinson's disease, multiple sclerosis or amyotrophic lateral sclerosis, to see if it can influence neurodegeneration could reveal their impact on neuropsychopathol- 
ogies. Screening for epigenetics compounds as DNA methylation and non-coding RNA action that can be altered is also required. Integration of genomics and epigenomics could better explain the chronic stress-related psychopathologies.

Acknowledgments This study was supported by the European Commission Framework 6 Integrated Project NEWMOOD (LSHMCT2004-503474) and Polish Ministry of Science and Higher Education Grant "Iuventus Plus" IP2011 030371. We appreciate Dr. Timothy A. Hinsley (Department of Computer Science, University of Manchester, UK) for assistance in processing of microarray data.

Conflict of Interest The authors have no conflict of interest regarding this report.

Open Access This article is distributed under the terms of the Creative Commons Attribution License which permits any use, distribution, and reproduction in any medium, provided the original author(s) and the source are credited.

\section{References}

Aguilera G, Nikodemova M, Wynn PC, Catt KJ (2004) Corticotropin releasing hormone receptors: two decades later. Peptides 25:319 329

Airan RD, Meltzer LA, Roy M, Gong Y, Chen H, Deisseroth K (2007) High-speed imaging reveals neurophysiological links to behavior in an animal model of depression. Science 317:819-823

Alfonso J, Fernandez ME, Cooper B, Flugge G, Frasch AC (2005) The stress-regulated protein M6a is a key modulator for neurite outgrowth and filopodium/spine formation. Proc Natl Acad Sci U S A 102:17196-17201

Amat J, Baratta MV, Paul E, Bland ST, Watkins LR, Maier SF (2005) Medial prefrontal cortex determines how stressor controllability affects behavior and dorsal raphe nucleus. Nat Neurosci 8:365371

Andrus BM, Blizinsky K, Vedell PT, Dennis K, Shukla PK, Schaffer DJ, Radulovic J, Churchill GA, Redei EE (2012) Gene expression patterns in the hippocampus and amygdala of endogenous depression and chronic stress models. Mol Psychiatry 17:49-61

Arnsten AF (2009) Stress signalling pathways that impair prefrontal cortex structure and function. Nat Rev Neurosci 10:410-422

Aston C, Jiang L, Sokolov BP (2005) Transcriptional profiling reveals evidence for signaling and oligodendroglial abnormalities in the temporal cortex from patients with major depressive disorder. Mol Psychiatry 10:309-322

Aubry JM, Bartanusz V, Jezova D, Belin D, Kiss JZ (1999) Single stress induces long-lasting elevations in vasopressin mRNA levels in CRF hypophysiotrophic neurones, but repeated sess is required to modify AVP immunoreactivity. J Neuroendocrinol 11:377-384

Bale TL, Contarintro A, Smith GW, Chan R, Gold LH, Sawchenko PE, Koob GF, Vale WW, Lee KF (2000) Mice deficient for corticotropin-releasing hormone receptor-2 display anxiety-like behaviour and are hypersensitive to stress. Nat Genet 24:410-414

Balschun D, Moechars D, Callaerts-Vegh Z, Vermaercke B, Van Acker N, Andries L, D'Hooge R (2010) Vesicular glutamate transporter VGLUT1 has a role in hippocampal long-term potentiation and spatial reversal learning. Cereb Cortex 20:684-693
Banasr M, Duman RS (2007) Regulation of neurogenesis and gliogenesis by stress and antidepressant treatment. CNS Neurol Disord Drug Targets 6:311-320

Bekris S, Antoniou K, Daskas S, Papadopoulou-Daifoti Z (2005) Behavioural and neurochemical effects induced by chronic mild stress applied to two different rat strains. Behav Brain Res 161:45-59

Benjamini Y, Hochberg Y (1995) Controlling the false discovery rate: a practical and powerful approach to multiple testing. J R Statist Soc B 57:289-300

Bergstrom A, Jayatissam MN, Mork A, Wiborg O (2008) Stress sensitivity and resilience in the chronic mild stress rat model of depression; an in situ hybridization study. Brain Res 1196:41-52

Błaszczyk JW, Tajchert K, Łapo I, Sadowski B (2000) Acoustic startle and open-field behavior in mice bred for magnitude of swim analgesia. Physiol Behav 70:471-476

Blevins G, Macaulay R, Harder S, Fladeland D, Yamashita T, Yazaki M, Hamidi Asl K, Benson MD, Donat JR (2003) Oculoleptomeningeal amyloidosis in a large kindred with a new transthyretin variant Tyr69His. Neurol 60:1625-1630

Blume A, Torner L, Liu Y, Subburaju S, Aguilera G, Neumann ID (2009) Prolactin activates mitogen-activated protein kinase signaling and corticotropin releasing hormone transcription in rat hypothalamic neurons. Endocrinol 150:1841-1849

Boks MPM, Hoogendoorn M, Jungerius BJ, Bakker SC, Sommer IE, Sinke RJ, Ophoff RA, Kahn RS (2008) Do mood symptoms subdivide the schizophrenia phenotype? Associationof the GMP6A gene with a depression subgroup. Am J Med Genet B Neuropsychiatr Genet 147B:707-711

Breier A, Davis OR, Buchanan RW (1991) Alprazolam attenuates metabolic stress-induced neuroendocrine and behavioral effects in humans. Psychopharmacol 104:479-484

Brown SM, Henning S, Wellman CL (2005) Mild, short-term stress alters dendritic morphology in rat medial prefrontal cortex. Cereb Cortex 15:1714-1722

Butler RK, Finn DP (2009) Stress-induced analgesia. Prog Neurobiol $88: 184-202$

Cahoy JD, Emery B, Kaushal A, Foo LC, Zamanian JL, Christopherson KS, Xing Y, Lubischer JL, Krieg PA, Krupenko SA, Thompson WJ, Barres BA (2008) A transcriptome database for astrocytes, neurons, and oligodendrocytes: a new resource for understanding brain development and function. J Neurosci 28:264-278

Ceccatelli S, Orazzo C (1993) Effect of different types of stressors on peptide messenger ribonucleic acids in the hypothalamic paraventricular nucleus. Acta Endocrinol 128:485-492

Coste SC, Kesterson RA, Heldwein KA, Stevens SL, Heard AD, Hollis JH, Murray SE, Hill JK, Pantely GA, Hohimer AR, Hatton DC, Phillips TJ, Finn DA, Low MJ, Rittenberg MB, Stenzel P, Stenzel-Poore MP (2000) Abnormal adaptations to stress and impaired cardiovascular function in mice lacking corticotropinreleasing hormone receptor-2. Nat Genet 24:403-409

Cummings JL (1992) Depression and Parkinson's disease: a review. Am J Psychiatry 149:443-454

Czeh B, Perez-Cruz C, Fuchs E, Flugge G (2008) Chronic stressinduced cellular changes in the medial prefrontal cortex and their potential clinical implications: Does hemisphere location matter? Behav Brain Res 190:1-13

D'Aquila PS, Brain P, Willner P (1994) Effects of chronic mild stress on performance in behavioural tests relevant to anxiety and depression. Physiol Behav 56:861-867

Denny JB, Polan-Curtain J, Ghuman A, Wayner MJ, Armstrong DL (1990) Calpain inhibitors block long-term potentiation. Brain Res 534:317-320

Deutch AY (1993) Prefrontal cortical dopamine systems and the elaboration of functional corticostriatal circuits: implications for schizophrenia and Parkinson's disease. J Neural Transm Gen Sect 91:197-221 
Dobner PR (2005) Multitasking with neurotensin in the central nervous system. Cell Mol Life Sci 62:1946-1963

Dohrenwend BP (1994) Psychology, psychologists, and psychiatric epidemiology. Acta Psych Scan 385:13-20

Dolan RJ, Bench CJ, Brown RG, Scott LC, Frackowiak RS (1994) Neuropsychological dysfunction in depression: the relationship to regional cerebral blood flow. Psych Med 24:849-857

Drevets WC (2000) Neuroimaging studies of mood disorders. Biol Psychiatry 48:813-829

Drevets WC, Price JL, Simpson JR Jr, Todd RD, Reich T, Vannier M, Raichle ME (1997) Subgenual prefrontal cortex abnormalities in mood disorders. Nature 386:824-827

Elizalde N, Gil-Beam FJ, Ramirez MJ, Aisa B, Lasheras B, Del Rio J, Tordera RM (2008) Long-lasting behavioral effects and recognition memory deficit induced by chronic mild stress in mice: effect of antidepressant treatment. Psychopharmacol 199:1-14

Fibiger HC (1995) Neurobiology of depression: focus on dopamine. Adv Bioch Psychopharmacol 49:1-17

Friedrich P (2004) The intriguing $\mathrm{Ca} 2+$ requirement of calpain activation. Biochem Biophys Res Commun 323:1131-1133

Frodl TS, Koutsouleris N, Bottlender R, Born C, Jager M, Scupin I, Reiser M, Moller HJ, Meisenzahl EM (2008) Depression-related variation in brain morphology over 3 years: effects of stress? Arch Gen Psychiatry 65:1156-1165

Fujikawa T, Soya H, Tamashiro KL, Sakai RR, McEwen BS, Nakai N, Ogata M, Suzuki I, Nakashima K (2004) Prolactin prevents acute stress-induced hypocalcemia and ulcerogenesis by acting in the brain of rat. Endocrinol 145:2006-2013

Garcia-Garcia AL, Elizalde N, Matrov D, Harro J, Wojcik SM, Venzala E, Ramirez MJ, Del Rio J, Tordera RM (2009) Increased vulnerability to depressive-like behavior of mice with decreased expression of VGLUT1. Biol Psychiatry 66:275-282

Garzuly F, Vidal R, Wisniewski T, Brittig F, Budka H (1996) Familial meningocerebrovascular amyloidosis, Hungarian type, with mutant transthyretin (TTR Asp18Gly). Neurol 47:1562-1567

Gould NF, Holmes MK, Fantie BD, Luckenbaugh DA, Pine DS, Gould TD, Burgess N, Manji HK, Zarate CA Jr (2007) Performance on a virtual reality spatial memory navigation task in depressed patients. Am J Psychiatry 164:516-519

Gronli J, Fiske E, Murison R, Bjorvatn B, Sorensen E, Ursin R, Portas CM (2007) Extracellular levels of serotonin and GABA in the hippocampus after chronic mild stress in rats. A microdialysis study in an animal model of depression. Behav Brain Res 181:42-51

Hamon M (2006) Science vision. University of Maastricht

Han JS, Bizon JL, Chun HJ, Maus CE, Gallagher M (2002) Decreased glucocorticoid receptor mRNA and dysfunction of HPA axis in rats after removal of the cholinergic innervation to hippocampus. Eur J Neurosci 16:1399-1404

Herman JP, Figueiredo H, Mueller NK, Ulrich-Lai Y, Ostrander MM, Choi DC, Cullinan WE (2003) Central mechanisms of stress integration: hierarchical circuitry controlling hypothalamopituitary-adrenocortical responsiveness. Front Neuroendocrinol 24:151-180

Hugues S, Deschaux O, Garcia R (2004) Postextinction infusion of a mitogen-activated protein kinase inhibitor into the medial prefrontal cortex impairs memory of the extinction of conditioned fear. Learn Mem 11:540-543

Izquierdo A, Wellman CL, Holmes A (2006) Brief uncontrollable stress causes dendritic retraction in infralimbic cortex and resistance to fear extinction in mice. J Neurosci 26:5733-5738

Jayatissa MN, Bisgaard CE, West MJ, Wiborg O (2008) The number of granule cells in rat hippocampus is reduced after chronic mild stress and re-established after chronic escitalopram treatment. Neuropharmacol 54:530-541

Joels M, Baram TZ (2009) The neuro-symphony of stress. Nat Rev Neurosci 10:459-466
Joels M, Karst H, Krugers HJ, Lucassen PJ (2007) Chronic stress: implications for neuronal morphology, function and neurogenesis. Front Neuroendocrinol 28:72-96

Jones LA, Skare JC, Cohen AS, Harding JA, Milunsky A, Skinner M (1992) Familial amyloidotic polyneuropathy: a new transthyretin position 30 mutation (alanine for valine) in a family of German descent. Clin Genet 41:70-73

Juszczak GR, Sliwa AT, Wolak P, Tymosiak-Zielinska A, Lisowski P, Swiergiel AH (2006) The usage of video analysis system for detection of immobility in the tail suspension test in mice. Pharmacol Biochem Behav 85:332-338

Juszczak GR, Błaszczyk J, Sadowski B, Sliwa AT, Wolak P, TymosiakZielinska A, Lisowski P, Swiergiel AH (2008a) Lipopolysaccharide does not affect acoustic startle reflex in mice. Brain Behav Immun 222:74-79

Juszczak GR, Lisowski P, Sliwa AT, Swiergiel AH (2008b) Computer assisted video analysis of swimming performance in a forced swim test: simultaneous assessment of duration of immobility and swimming style in mice selected for high and low swimstress induced analgesia. Physiol Behav 95:400-407

Karssen AM, Her S, Li JZ, Patel PD, Meng F, Bunney WE Jr, Jones EG, Watson SJ, Akil H, Myers RM, Schatzberg AF, Lyons DM (2007) Stress-induced changes in primate prefrontal profiles of gene expression. Mol Psychiatry 12:1089-1102

Koob GF (2008) A role for brain stress systems in addiction. Neuron 59:11-34

Lafrance M, Roussy G, Belleville K, Maeno H, Beaudet N, Wada K, Sarret P (2010) Involvement of NTS2 receptors in stress-induced analgesia. Neurosci 166:639-652

Landers KA, McKinnon BD, Li H, Subramaniam VN, Mortimer RH, Richard K (2009) Carrer-mediated thyroid hormone transport into placenta by placental transthyretin. J Clin Endocrinol Metab 7:2610-2616

Li CS, Sinha R (2008) Inhibitory control and emotional stress regulation: neuroimaging evidence for frontal-limbic dysfunction in psycho-stimulant addiction. Neurosci Biobehav Rev 32:581-597

Lisowski P, Robakowska-Hyzorek D, Blitek A, Kaczmarek MM, Gajewska A, Kochman H, Zwierzchowski L, Ziecik AJ, Kochman K (2008a) Development of real-time PCR assays in the study of gonadotropin subunits, follistatin and prolactin genes expression in the porcine anterior pituitary during the preovulatory period. Neuro Endocrinol Lett 29:958-964

Lisowski P, Pierzchała M, Gościk J, Pareek CS, Zwierzchowski L (2008b) Evaluation of reference genes for studies of gene expression in the bovine liver, kidney, pituitary, and thyroid. J Appl Genet 49:367-372

Lisowski P, Juszczak GR, Goscik J, Wieczorek M, Zwierzchowski L, Swiergiel AH (2011) Effect of chronic mild stress on hippocampal transcriptome in mice selected for high and low stress-induced analgesia and displaying different emotional behaviors. Eur Neuropsychopharmacol 21:45-62

Lisowski P, Stankiewicz AM, Goscik J, Wieczorek M, Zwierzchowski L, Swiergiel AH (2012) Selection for stress responsiveness affects the mouse hippocampal transcriptome. J Mol Neurosci 47:101112

Liu F, Grundke-Iqbal I, Iqbal K, Oda Y, Tomizawa K, Gong CX (2005) Truncation and activation of calcineurin A by calpain I in Alzheimer disease brain. J Biol Chem 280:37755-37762

Lucassen PJ, Heine VM, Muller MB, van der Beek EM, Wiegant VM, De Kloet ER, Joels M, Fuchs E, Swaab DF, Czeh B (2006) Stress, depression and hippocampal apoptosis. CNS \& Neurol Disord Drug Targets 5:531-546

Lynch G, Baudry M (1984) The biochemistry of memory: a new and specific hypothesis. Science 224:1057-1063

Makino S, Smith MA, Gold PW (1995) Increased expression of corticotropin-releasing hormone and vasopressin messenger 
ribonucleic acid (mRNA) in the hypothalamic paraventricular nucleus during repeated stress: association with reduction in glucocorticoid receptor mRNA levels. Endocrinol 136:3299-3309

Malmberg AB, Chen C, Tonegawa S, Basbaum AI (1997) Preserved acute pain and reduced neuropathic pain in mice lacking PKCgamma. Science 278:279-283

Martins-de-Souza D, Harris LW, Guest PC, Turck CW, Bahn S (2010) The role of proteomics in depression research. Eur Arch Psychiatry Clin Neurosci 260:499-506

Mazure CM, Kincare P, Schaffer CE (1995) DSM-III-R Axis IV: clinician reliability and comparability to patients' reports of stressor severity. Psychiatry 58:56-64

McEwen BS (2004) Protection and damage from acute and chronic stress: allostasis and allostatic overload and relevance to the pathophysiology of psychiatric disorders. Ann N Y Acad Sci 1032:1-7

McEwen BS (2006) Protective and damaging effects of stress mediators: central role of the brain. Dialogues Clin Neurosci 8:367-381

Meeus M, Nijs J, Van de Wauwer N, Toeback L, Truijen S (2008) Diffuse noxious inhibitory control is delayed in chronic fatigue syndrome: an experimental study. Pain 139:439-448

Miner LH, Jedema HP, Moore FW, Blakely RD, Grace AA, Sesack SR (2006) Chronic stress increases the plasmalemmal distribution of the norepinephrine transporter and the coexpression of tyrosine hydroxylase in norepinephrine axons in the prefrontal cortex. J Neurosci 26:1571-1578

Mizoguchi K, Yuzurihara M, Ishige A, Sasaki H, Chui DH, Tabira T (2000) Chronic stress induces impairment of spatial working memory because of prefrontal dopaminergic dysfunction. J Neurosci 20:1568-1574

Mizoguchi K, Yuzurihara M, Ishige A, Sasaki H, Tabira T (2002) Chronic stress impairs rotarod performance in rats: implications for depressive state. Pharmacol Biochem Behav 71:79-84

Muller MB, Zimmermann S, Sillaber I, Hagemeyer TP, Deussing JM, Timpl P, Kormann MS, Droste SK, Kuhn R, Reul JM, Holsboer F, Wurst W (2003) Limbic corticotropin-releasing hormone receptor 1 mediates anxiety-related behavior and hormonal adaptation to stress. Nat Neurosci 6:1100-1107

Murakami T, Yi S, Yamamoto K, Maruyama S, Araki S (1992) Familial amyloidotic polyneuropathy: report of patients heterozygous for the transthyretin Gly42 gene. Annal Neurol 31:340-342

Murakami T, Tachibana S, Endo Y, Kawai R, Hara M, Tanase S, Ando M (1994) Familial Carpal-Tunnel Syndrome Due to Amyloidogenic Transthyretin His-114 Variant. Neurol 44:315-318

Nishith P, Griffin MG, Poth TL (2002) Stress-induced analgesia: prediction of posttraumatic stress symptoms in battered versus nonbattered women. Biol Psychiatry 51:867-874

Ochedalski T, Rabadan-Diehl C, Aguilera G (1998) Interaction between glucocorticoids and corticotropin releasing hormone $(\mathrm{CRH})$ in the regulation of the pituitary $\mathrm{CRH}$ receptor in vivo in the rat. J Neuroendocrinol 10:363-369

Page AJ, Young RL, Martin CM, Umaerus M, O'Donnell TA, Cooper NJ, Coldwell JR, Hulander M, Mattsson JP, Lehmann A, Blackshaw LA (2005) Metabotropic glutamate receptors inhibit mechanosensitivity in vagal sensory neurons. Gastroenterol 128:402-410

Panocka I, Marek P, Sadowski B (1986a) Differentiation of neurochemical basis of stress-induced analgesia in mice by selective breeding. Brain Res 397:156-160

Panocka I, Marek P, Sadowski B (1986b) Inheritance of stress-induced analgesia in mice. Selective breeding study. Brain Res 397:152155

Panocka I, Massi M, Łapo I, Swiderski T, Kowalczyk M, Sadowski B (2001) Antidepressant-type effect of the NK3 tachykinin receptor agonist aminosenktide in mouse lines differing in endogenous opioid system activity. Peptides 22:1037-1042

Pascucci T, Ventura R, Latagliata EC, Cabib S, Puglisi-Allegra S (2007) The medial prefrontal cortex determines the accumbens dopamine response to stress through the opposing influences of norepinephrine and dopamine. Cereb Cortex 17:2796-2804

Pasterkamp RJ, Giger RJ (2009) Semaphorin function in neural plasticity and disease. Curr Opin Neurobiol 19:263-274

Pfaffl MW (2001) A new mathematical model for relative quantification in real-time RT-PCR. Nucleic Acids Res 29:e45

Pielsticker A, Haag G, Zaudig M, Lautenbacher S (2005) Impairment of pain inhibition in chronic tension-type headache. Pain 118: 215-223

Pirot S, Jay TM, Glowinski J, Thierry AM (1994) Anatomical and electrophysiological evidence for an excitatory amino acid pathway from the thalamic mediodorsal nucleus to the prefrontal cortex in the rat. Eur J Neurosci 6:1225-1234

Rajkowska G (2000) Postmortem studies in mood disorders indicate altered numbers of neurons and glial cells. Biol Psychiatry 48:766-777

Ramos BP, Arnsten AF (2007) Adrenergic pharmacology and cognition: focus on the prefrontal cortex. Pharmacol Ther 113:523-536

Robbins TW (1996) Dissociating executive functions of the prefrontal cortex. Philos Trans R Soc Lond B Biol Sci 351:1463-1470

Sanacora G, Gueorguieva R, Epperson CN, Wu YT, Appel M, Rothman DL, Krystal JH, Mason GF (2004) Subtype-specific alterations of gamma-aminobutyric acid and glutamate in patients with major depression. Arch Gen Psychiatry 61:705-713

Saraiva MJ, Almeida Mdo R, Sherman W, Gawinowicz M, Costa P, Costa PP, Goodman DS (1992) A new transthyretin mutation associated with amyloid cardiomyopathy. Am J Hum Genet 50:1027-1030

Seta KA, Jansen HT, Kreitel KD, Lehman M, Behbehani MM (2001) Cold water swim stress increases the expression of neurotensin mRNA in the lateral hypothalamus and medial preoptic regions of the rat brain. Brain Res Mol Brain Res 86:145-152

Sousa JC, Grandela C, Fernandez-Ruiz J, de Miguel R, de Sousa L, Magalhaes AI, Saraiva MJ, Sousa N, Palha JA (2004) Transthyretin is involved in depression-like behaviour and exploratory activity. J Neurochem 88:1052-1058

Staubli U, Larson J, Thibault O, Baudry M, Lynch G (1988) Chronic administration of a thiol-proteinase inhibitor blocks long-term potentiation of synaptic responses. Brain Res 444:153-158

Staud R, Robinson ME, Vierck CJ Jr, Cannon RC, Mauderli AP, Price DD (2003) Ratings of experimental pain and pain-related negative affect predict clinical pain in patients with fibromyalgia syndrome. Pain 105:215-222

Stern JN, Keskin DB (2008) Strategies for the identification of loci responsible for the pathogenesis of multiple sclerosis. Cell Mol Biol Lett 13:656-666

Teixeira PF, Cerca F, Santos SD, Saraiva MJ (2006) Endoplasmic reticulum stress associated with extracellular aggregates. Evidence from transthyretin deposition in familial amyloid polyneuropathy. J Biol Chem 281:21998-22003

Tordera RM, Totterdell S, Wojcik SM, Brose N, Elizalde N, Lasheras B, Del Rio J (2007) Enhanced anxiety, depressive-like behaviour and impaired recognition memory in mice with reduced expression of the vesicular glutamate transporter 1 (VGLUT1). Eur J Neurosci 25:281-290

Tordera RM, Garcia-Garcia AL, Elizalde N, Segura V, Aso E, Venzala E, Ramirez MJ, Del Rio J (2011) Chronic stress and impaired glutamate function elicit a depressive-like phenotype and common changes in gene expression in the mouse frontal cortex. Eur Neuropsychopharmacol 21:23-32

Torner L, Toschi N, Pohlinger A, Landgraf R, Neumann ID (2001) Anxiolytic and anti-stress effects of brain prolactin: improved efficacy of antisense targeting of the prolactin receptor by molecular modeling. J Neurosci 21:3207-3214

Uezato A, Meador-Woodruff JH, McCullumsmith RE (2009) Vesicular glutamate transporter mRNA expression in the medial temporal 
lobe in major depressive disorder, bipolar disorder, and schizophrenia. Bipolar Disord 11:711-725

Vanderklish PW, Bahr BA (2000) The pathogenic activation of calpain: a marker and mediator of cellular toxicity and disease states. Int $\mathrm{J}$ Exp Pathol 81:323-339

Vanderklish PW, Krushel LA, Holst BH, Gally JA, Crossin KL, Edelman GM (2000) Marking synaptic activity in dendritic spines with a calpain substrate exhibiting fluorescence resonance energy transfer. Proc Natl Acad Sci U S A 97:2253-2258

Vertes RP (2006) Interactions among the medial prefrontal cortex, hippocampus and midline thalamus in emotional and cognitive processing in the rat. Neuroscience 142:1-20

Wang YL, Barbacioru C, Hyland F, Xiao WM, Hunkapiller KL, Blake J, Chan F, Gonzalez C, Zhang L, Samaha RR (2006) Large scale realtime PCR validation on gene expression measurements from two commercial long-oligonucleotide microarrays. Bmc Genomics 7:59

Warner-Schmidt JL, Duman RS (2006) Hippocampal neurogenesis: opposing effects of stress and antidepressant treatment. Hippocampus 16:239-249
Willner P, Towell A, Sampson D, Sophokleous S, Muscat R (1987) Reduction of sucrose preference by chronic unpredictable mild stress, and its restoration by a tricyclic antidepressant. Psychopharmacol 93:358-364

Wood GE, Norris EH, Waters E, Stoldt JT, McEwen BS (2008) Chronic immobilization stress alters aspects of emotionality and associative learning in the rat. Behav Neurosci 122:282-292

Wu HY, Lynch DR (2006) Calpain and synaptic function. Mol Neurobiol 33:215-236

Yamashita N, Morita A, Ushida Y, Nakamura F, Usui H, Ohshima T, Taniguchi M, Honnorat J, Thomasset N, Takei K et al (2007) Regulation of spine development by semaphorin3A through cyclin-dependent kinase 5 phosphorylation of collapsin response mediator protein 1. J Neurosci 27:12546-12554

Zimmermann U, Spring K, Wittchen HU, Himmerich H, Landgraf R, Uhr M, Holsboer F (2004) Arginine vasopressin and adrenocorticotropin secretion in response to psychosocial stress is attenuated by ethanol in sons of alcohol-dependent fathers. J Psychiatr Res 38:385-393 